\title{
Cloud and aerosol classification for 2.5 years of MAX-DOAS observations in Wuxi (China) and comparison to independent data sets
}

\author{
Y. Wang ${ }^{1,2}$, M. Penning de Vries ${ }^{1}$, P. H. Xie ${ }^{2}$, S. Beirle ${ }^{1}$, S. Dörner ${ }^{1}$, J. Remmers ${ }^{1}$, A. Li ${ }^{2}$, and T. Wagner ${ }^{1}$ \\ ${ }^{1}$ Max Planck Institute for Chemistry, Hahn-Meitner-Weg 1, 55128 Mainz, Germany \\ ${ }^{2}$ Anhui Institute of Optics and Fine Mechanics, Chinese Academy of Sciences, Hefei, China \\ Correspondence to: Y. Wang (y.wang@mpic.de)
}

Received: 31 March 2015 - Published in Atmos. Meas. Tech. Discuss.: 6 May 2015

Revised: 20 November 2015 - Accepted: 23 November 2015 - Published: 10 December 2015

\begin{abstract}
Multi-axis differential optical absorption spectroscopy (MAX-DOAS) observations of trace gases can be strongly influenced by clouds and aerosols. Thus it is important to identify clouds and characterize their properties. In a recent study Wagner et al. (2014) developed a cloud classification scheme based on the MAX-DOAS measurements themselves with which different "sky conditions" (e.g., clear sky, continuous clouds, broken clouds) can be distinguished. Here we apply this scheme to long-term MAX-DOAS measurements from 2011 to 2013 in Wuxi, China $\left(31.57^{\circ} \mathrm{N}\right.$, $\left.120.31^{\circ} \mathrm{E}\right)$. The original algorithm has been adapted to the characteristics of the Wuxi instrument, and extended towards smaller solar zenith angles (SZA). Moreover, a method for the determination and correction of instrumental degradation is developed to avoid artificial trends of the cloud classification results. We compared the results of the MAX-DOAS cloud classification scheme to several independent measurements: aerosol optical depth from a nearby Aerosol Robotic Network (AERONET) station and from two Moderate Resolution Imaging Spectroradiometer (MODIS) instruments, visibility derived from a visibility meter and various cloud parameters from different satellite instruments (MODIS, the Ozone Monitoring Instrument (OMI) and the Global Ozone Monitoring Experiment (GOME-2)). Here it should be noted that no quantitative comparison between the MAX-DOAS results and the independent data sets is possible, because (a) not exactly the same quantities are measured, and (b) the spatial and temporal sampling is quite different. Thus our comparison is performed in a semi-quantitative way: the MAXDOAS cloud classification results are studied as a function
\end{abstract}

of the external quantities. The most important findings from these comparisons are as follows: (1) most cases characterized as clear sky with low or high aerosol load were associated with the respective aerosol optical depth (AOD) ranges obtained by AERONET and MODIS; (2) the observed dependences of MAX-DOAS results on cloud optical thickness and effective cloud fraction from satellite confirm that the MAX-DOAS cloud classification scheme is sensitive to cloud (optical) properties; (3) the separation of cloudy scenes by cloud pressure shows that the MAX-DOAS cloud classification scheme is also capable of detecting high clouds; (4) for some cloud-free conditions, especially with high aerosol load, the coincident satellite observations indicated optically thin and low clouds. This finding indicates that the satellite cloud products contain valuable information on aerosols.

\section{Introduction}

In the last decade, multi-axis (MAX-) differential optical absorption spectroscopy (DOAS) has received considerable attention due to its application to the retrieval of vertical distributions of trace gases and aerosols (Hönninger et al., 2004; Bobrowski et al., 2003; Pikelnaya et al., 2007; Sinreich et al., 2007; Theys et al., 2007; Clémer et al., 2009, 2010; Wagner et al., 2011; Vlemmix et al., 2010, 2011, 2015). Scattered sunlight spectra recorded by MAX-DOAS instruments at multiple elevation angles are analyzed using DOAS (Platt and Stutz, 2008) to acquire slant column densities (SCDs) of several trace gases; the slant column density represents 
the trace gas concentration integrated along the atmospheric light path. Different inversion approaches, e.g., based on look-up tables or optimal estimation, are applied to derive tropospheric profiles of trace gases and aerosols from the measured SCDs (e.g., Wittrock et al., 2004; Wagner et al., 2004, 2011; Heckel et al., 2005; Frieß et al., 2006, 2011; Irie et al., 2008, 2011; Clémer et al., 2010; Li et al., 2010, 2013; Yilmaz, 2012; Hartl and Wenig, 2013; Vlemmix et al., 2015). Cloud-free sky is an ideal condition for the profile inversion, whereas under cloudy skies the atmospheric light paths are complicated, especially for rapidly changing cloud conditions. In principle it would be possible to include clouds in the radiative transfer simulations, but usually the necessary information on cloud properties is not available (e.g., Erle et al., 1995; Wagner et al., 1998, 2002, 2004; Winterrath et al., 1999). So it is important to identify and classify clouds and aerosols for each measurement in order to characterize the quality of the measurement result. In this study, we refer to the presence and properties of clouds and aerosols as "sky conditions". Cloud information derived from MAXDOAS observations - instead of other sources like e.g., visual inspection or camera images - is very important, because it can be directly assigned to individual MAX-DOAS observations without any spatiotemporal interpolation and without requiring the installation of additional instrumentation. This will become especially important for harmonized MAX-DOAS data processing in global monitoring networks of tropospheric species in the future.

Recently, Wagner et al. (2014) developed a sophisticated cloud classification scheme and applied it to MAXDOAS observations obtained during the Cabauw Intercomparison campaign of Nitrogen Dioxide measuring Instruments (CINDI) that took place in Cabauw, the Netherlands, in summer 2009 (Piters et al., 2012; see also http: //www.knmi.nl/samenw/cindi/). The algorithm differentiates between six primary sky conditions (varying between clear sky with low aerosol load to continuous cloud cover) attaching two secondary sky conditions of fog and optically thick clouds, based on the absolute values, temporal variability, viewing-angle dependency of a color index $(\mathrm{CI})$ and the radiance and the absorption of the oxygen $\operatorname{dimer}\left(\mathrm{O}_{4}\right)$.

The CI is defined as the ratio of radiances at different wavelengths; in this paper it is the ratio of radiances at 340 and $420 \mathrm{~nm}$ :

$\mathrm{CI}=\frac{R_{340}}{R_{420}}$,

with $R_{340}$ and $R_{420}$ the radiances measured at 340 and $420 \mathrm{~nm}$, respectively. In this definition high (low) CI values indicate blue (white) skies. The $\mathrm{CI}$ is sensitive to the presence of clouds and aerosols because of the different wavelength dependencies of Rayleigh scattering and particle scattering (Sarkissian et al., 1991; Takashima et al., 2009; Gielen et al., 2014; Wagner et al., 2014). Because of the much weaker wavelength dependence of scattering on particles, the CI de- creases in the presence of clouds and aerosols. Thus, from deviations of the CI from the clear sky values, the presence of clouds or aerosols can be deduced. Here it should be noted that this general dependence is strictly valid only for viewing directions close to the zenith. Thus for the discrimination of clear and cloudy sky, CI measurements made in zenith direction are used in our classification scheme (for exceptions at small SZA, see Sect. 2.3.3).

In addition, Wagner et al. (2014) found that the spread of $\mathrm{CI}$ values for different elevation angles strongly decreases in the presence of continuous clouds (i.e., homogenous cloud cover) (see also Gielen et al., 2014). Moreover, the temporal variation of the $\mathrm{CI}$ for one elevation angle, i.e., the quick iteration of cloudy and clear conditions, indicates the advection of broken clouds (Gielen et al., 2014; Wagner et al., 2014).

In addition to the $\mathrm{CI}$, the $\mathrm{O}_{4}$ absorption and radiance extracted from MAX-DOAS observations provide important information for the identification and characterization of clouds, especially for the presence of optically thick clouds (Wagner et al., 1998, 2002, 2014).

In this study, we adapted the scheme developed by Wagner et al. (2014) to long-term MAX-DOAS observations for about 2.5 years in Wuxi, China. The original scheme was basically unchanged but appropriate new threshold values were developed, taking into account the characteristics of the instrument at Wuxi. Because Wuxi is located at lower latitudes compared to Cabauw, the scheme was also extended towards smaller SZA, which led to the introduction of the new sky condition (exceptional continuous clouds) at low SZA. Also a method for the quantification and correction of the effects of instrumental degradation was developed, which becomes important for extended time series.

To verify the cloud classification scheme, the sky conditions identified by MAX-DOAS are compared to cloud and aerosol products from a variety of independent ground-based and satellite instruments, such as the Aerosol Robotic Network (AERONET) (Holben et al., 1998, 2001), a visibility meter, the Ozone Monitoring Instrument (OMI) (Levelt et al., 2006a, b), the Global Ozone Monitoring Experiment (GOME-2) (Callies et al., 2000; Munro et al., 2006, 2015) and the two Moderate Resolution Imaging Spectroradiometer (MODIS) instruments (http://modis.gsfc.nasa.gov/) (Kaufmann et al., 2002). Here it should, however, be noted that no direct comparison between the MAX-DOAS results and the independent data sets is possible because of two reasons.

a. The same quantities are not measured: the MAX-DOAS classification results are complex quantities (e.g., categories of broken clouds or continuous clouds), which cannot directly be compared to the independent data sets. Thus only semi-quantitative conclusions can be drawn, e.g., confirming that the probability for the detection of continuous clouds from MAX-DOAS in- 
creases with increasing cloud fraction derived from the satellite observations.

b. The temporal and spatial resolution is different: the satellite observations typically cover an extended area, but are valid only for the time of the satellite overpass. Also the AERONET observations are not made at exactly the same location but about $18 \mathrm{~km}$ southwest of the Wuxi MAX-DOAS site. The visibility meter covers only the layers close to the surface.

In spite of these fundamental difficulties, the comparison to the independent data sets is still very important, because from the general dependencies derived from the comparisons it can be concluded whether the classification scheme yields reasonable results or not. Here it should also be noted that to our knowledge, no data set exists which could be used for a direct and quantitative validation of our classification scheme.

The paper is organized as follows: in Sect. 2 we describe the properties of the MAX-DOAS instrument in Wuxi, China, and the retrieval of the quantities used for the cloud classification. Then we describe the principles and procedures to adapt and improve the automatic cloud classification scheme. We also introduce the independent data sets used for comparison. Section 3 presents the results of identified sky conditions and their comparisons with independent data sets. In Sect. 4 the discussion and conclusions are given.

\section{Data sets and methods}

\subsection{MAX-DOAS instrument}

A Mini-MAX-DOAS instrument (Li, et al., 2007, see Fig. 1a) is automatically operated and taken care of by the Wuxi Chinese Academy of Sciences Photonics corporation on the roof of an 11-story building in Wuxi, China $\left(31.57^{\circ} \mathrm{N}, 120.31^{\circ} \mathrm{E}\right.$; $50 \mathrm{~m}$ a.s.1., see Fig. 1b), from May 2011 to present. The data in the period until November 2013 are included in this work, except for the time between 15 December 2011 to 28 February 2012, when the instrument was not in operation. The instrument is designed to sequentially acquire scattered sunlight spectra at different elevation angles (the angle between the horizon and the viewing direction). The indoor computer controls the acquisition of spectra and pointing of the telescope. All the outdoor components are protected by a metal sealed box consisting of the entrance optics and a lightweight fiber-coupled spectrometer cooled by a Peltier element. In the entrance optics a stepper motor controls the elevation angles. The entrance optics consists of a quartz lens coupled to a quartz fiber bundle which leads the collected light into the spectrograph. The entrance optics has a field of view (FOV) of $\sim 0.4^{\circ}$. The light is dispersed by a crossed Czerny-Turner spectrometer (HR2000+, Ocean Optics Inc.) with a spectral resolution of $0.35 \mathrm{~nm}$ over a spectral range from 290

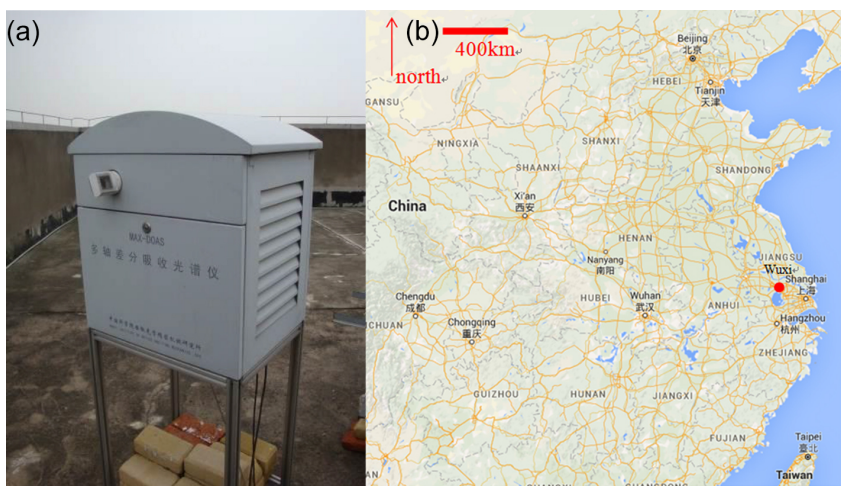

Figure 1. The photograph of the Mini-MAX-DOAS (a) in the Wuxi station marked by the red dot in the geographical map (b).

$425 \mathrm{~nm}$. A one-dimensional charge-coupled device (CCD) is used as the detector. During the observation period the instrument was pointed exactly to the north and performed measurements at sequences of five elevation angles $(5,10,20,30$ and $90^{\circ}$ ). A full elevation sequence usually took about $12 \mathrm{~min}$ depending on the received radiance. The CCD exposure time is automatically adjusted based on the scattered solar radiance to ensure $\sim 70 \%$ of the saturation level of the detector. 100 individual scans are averaged for each elevation angle to enhance the signal to noise ratio. For the measurement of background spectra (containing dark current and electronic offset) a light shade is used in the entrance optics. Individual background spectra are subtracted from the corresponding measured spectra to correct dark current and electronic offset. In this study only measurements for solar zenith angle $(\mathrm{SZA})<90^{\circ}$ are considered.

\subsection{Quantities from MAX-DOAS observations}

The cloud/aerosol classification is based on three quantities retrieved from the MAX-DOAS measurements: (1) radiance (indicating the brightness of the sky), (2) a color index (CI), i.e., the ratio of radiances at two wavelengths (indicating the color of the sky) and (3) the spectral absorption of the oxygen dimer (indicating changes of the atmospheric light paths, e.g., multiple scattering). Different sky conditions are defined by comparing these quantities and their temporal variation to threshold values, as in Wagner et al. (2014).

In the following sections, we will introduce each of the quantities and discuss their particularities. In particular, it has to be carefully elaborated how stable the instrument is over time to avoid instrumental degradation leading to artificial trends in the detected sky conditions.

\subsubsection{Radiance and color index}

The detector read-out of the MAX-DOAS measurements directly provides a spectrally resolved signal (in units of counts $\mathrm{s}^{-1}$ ), which is proportional to the observed radiances 
(a)

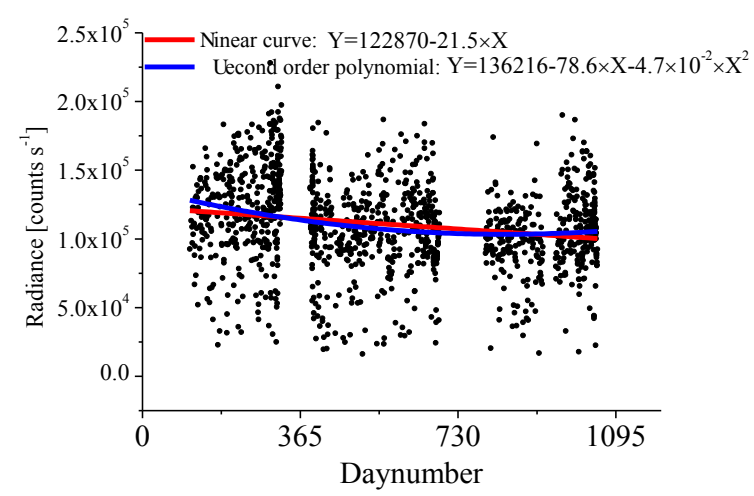

(b)

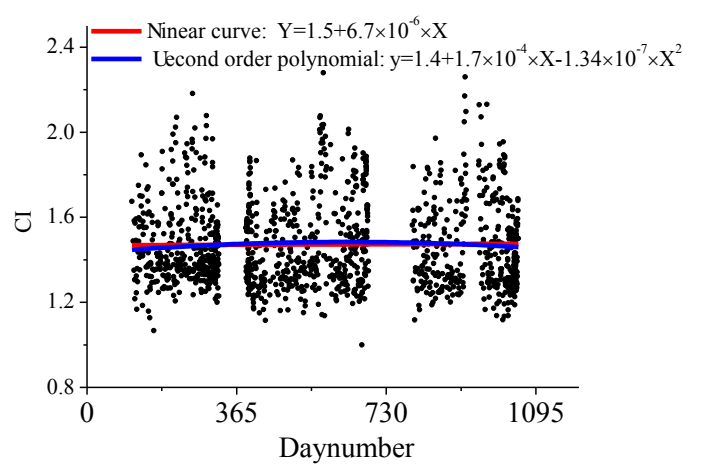

Figure 2. The radiance at $380 \mathrm{~nm}$ (a) and the color index $(340 / 420 \mathrm{~nm})(\mathbf{b})$ derived from MAX-DOAS observations in zenith view against the day number (the day number of 1 corresponds to 1 January 2011) for an SZA interval of 49 to $51^{\circ}$. The red and blue curves represent a linear fitted slope and second-order polynomial as functions of the day number, respectively.

(e.g., expressed in units of photons per area, time and solid angle). Here it should be noted that in the following that for the sake of simplicity, we will also use the term "radiance" for the measured signal (in units of counts s ${ }^{-1}$ ). In order to characterize a possible trend of the measured radiance (caused by changes of the instrumental characteristics), we investigated time series of radiances at $380 \mathrm{~nm}$ at zenith view for a small SZA interval ( 49 to $51^{\circ}$ ), as they are not affected by seasonal changes of the relative azimuth angle. The time series of the radiance together with a fitted linear slope and second-order polynomial is presented in Fig. 2a. The degradation of the measured radiance is appreciable: over the period of 2.5 years, a substantial decrease of the measured radiance of about $20 \%$ is found. To correct this long-term degradation of the radiance, we first divided the fitted polynomial by the mean value of the radiance measured on 25 July 2012 (the middle of the time period) to obtain the correction function, $f_{\mathrm{c}}$. Then we multiplied the measured zenith radiance of a given day with this correction function:

$R_{\mathrm{c}}(d)=R_{\mathrm{o}}(d) / f_{\mathrm{c}}(d)$.

Here, $R_{\mathrm{c}}$ is the corrected radiance, $R_{\mathrm{O}}$ is the original measured radiance and $d$ is the day number from 1 January 2011.

In contrast to the radiance, the degradation of the measured CI (the ratio of radiances at 340 and $420 \mathrm{~nm}$ ) is negligible, as shown in Fig. 2b. So we did not apply any degradation correction to the measured CI.

To account for the SZA dependence of the CI and measured radiance, both quantities are normalized by dividing the measured values by their respective clear sky reference values. But before the normalization can be applied, the measured CI and radiances have to be calibrated. The calibration is performed by comparing the measured values with the corresponding simulation results from radiative transfer model (RTM) for well-defined atmospheric conditions. As in Wag- ner et al. (2014) we chose measurements on clear days with low aerosol optical depth (AOD) for the calibration. We assumed an aerosol layer from the surface to $1 \mathrm{~km}$, an asymmetry parameter of 0.68 , a single-scattering albedo of 0.95 , an Ångström parameter of 1.0 and a surface albedo of $5 \%$. We used a slightly different AOD (0.14 at $440 \mathrm{~nm}$; Wagner et al. (2014) used 0.24), as this value was measured at the nearby AERONET station, Taihu (see Fig. 3a). The radiative transfer simulations using the McArtim RTM (Deutschmann et al., 2011) are performed for the SZA range of 1 to $90^{\circ}$ in steps of $1^{\circ}$. In Fig. 4 the CI and the radiance on the 3 clear days are compared to the corresponding radiative transfer simulation results (please note the different $y$ axes on the left and right side of the figures). For the CI, good agreement of the SZA dependencies is found (see Fig. 4a). Thus the calibration of the CI is simply performed by multiplication of the measured values with a proportionality constant $\alpha$, which in our case is 0.89 . In contrast to the CI, the SZA dependence of the measured and modeled radiances does not agree as well: for $\mathrm{SZA}<40^{\circ}$ measured radiances are much larger than the modeled radiances. This systematic difference is probably caused by the deviation of the true aerosol phase function from the Henyey-Greenstein parameterization (Henyey and Greenstein, 1941) used in the model simulations. For this reason, we determined the proportionality constant for the calibration of the radiance in the SZA interval between 50 and $81^{\circ}$ (note that no measurements at $\mathrm{SZA}>81^{\circ}$ were available during the selected days), for which the simulated radiances do not depend strongly on the assumed phase function. We derived a proportionality constant of $7.01 \times 10^{-7}$ counts $^{-1}$.

Because of the large discrepancy between measured and simulated radiances for $\mathrm{SZA}<40^{\circ}$, the simulated clear sky reference radiances cannot be used for the whole SZA range. Here it should be noted that for the radiative transfer simu- 

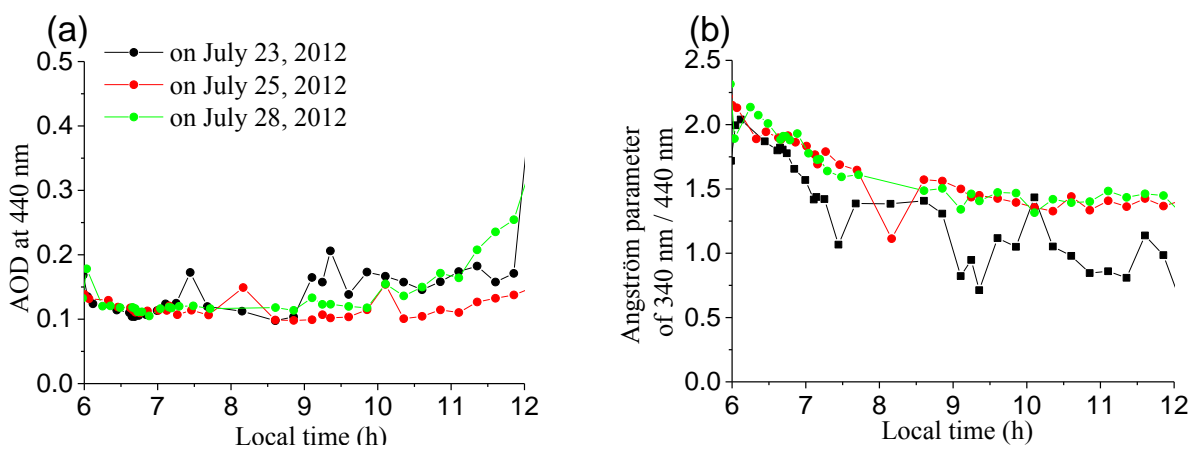

Figure 3. Time series of the AOD at $440 \mathrm{~nm}$ (a) and the Ångström parameter of $340 \mathrm{~nm}$ against $440 \mathrm{~nm}$ (b) from AERONET on 23,25 and 28 July, 2012.

(a)

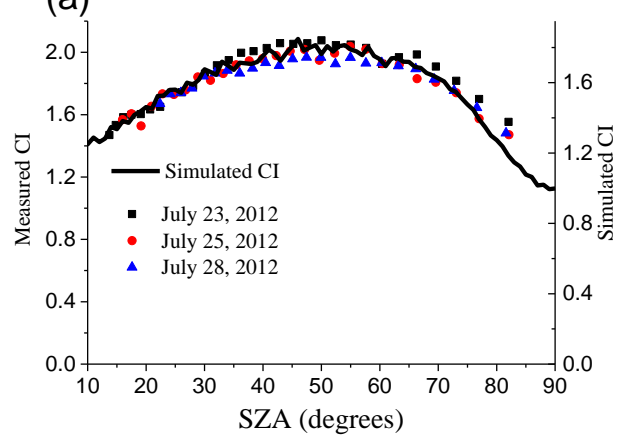

(b)

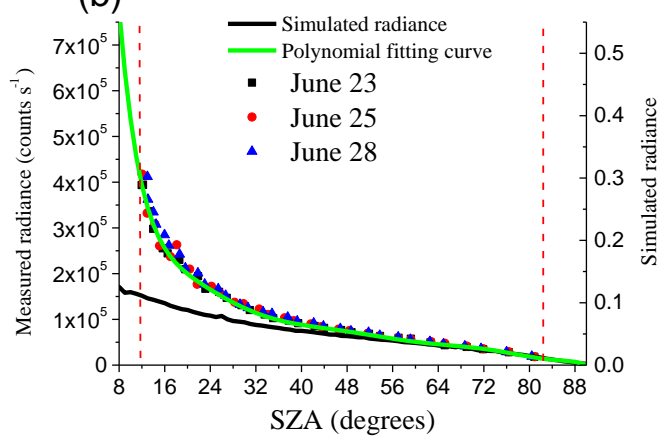

Figure 4. The comparisons of zenith measurements of (a) the CI (340/420 nm), and (b) the radiance at $380 \mathrm{~nm}$ for 3 clear half days with their corresponding values derived from radiative transfer simulations (black lines). In the subfigure (b) the green line indicates the polynomial fit of the measured radiance on the 3 half days; the red dashed lines indicate the SZA of 12 and $82^{\circ}$.

lations, in principle, instead of a simple Henyey-Greenstein parameterization, a Mie-phase function (based on the measurements at the nearby AERONET station at Taihu) could be used. However, we did not follow such an approach because of two reasons: first, the AERONET station is not fully representative of the MAX-DOAS measurements because of the distance of about $18 \mathrm{~km}$ to the Wuxi station. Second, the true aerosols might contain also non-spherical particles, and might change with time. Thus even a Mie-phase function will probably not well describe the observed SZA dependence; thus we took an empirical approach. First, we fitted a polynomial to the measured radiances (green line in Fig. 4b). Because no measurements for SZA $<12^{\circ}$ were available, a method to extrapolate the clear sky reference radiances to smaller SZA had to be found. Our first idea was to simply extend the fitted polynomial to SZA $<12^{\circ}$ (see green curve in Fig. 5). However, because of the strong dependence of the polynomial for small SZA, the corresponding errors would be quite large. Instead we decided to choose the average of the maximum and minimum radiances measured for all sky conditions (see blue curve in Fig. 5). This choice may appear somewhat arbitrary, but it is justified by the fact that for SZA between 12 and $81^{\circ}$ the average of the maximum and min- imum measured radiances for all measurements (clear and cloudy conditions) (see the magenta curve in Fig. 5) is similar to the clear sky reference values, indicated by the green curve. For SZA $>81^{\circ}$ (which is also not covered by the 3 half clear days) we used the simulation results as clear sky reference values. The clear sky reference values over the whole SZA range $\left(8-90^{\circ}\right)$ are indicated by the blue line in Fig. 5 . Normalized radiances are calculated from the calibrated radiance divided by the merged clear sky reference of the same SZA. Again it should be noted that the determination of the radiance reference values for $\mathrm{SZA}<40^{\circ}$ as described above is to some extent arbitrary. Thus future studies should aim to improve the calibration procedures for the measured radiance. Nevertheless, the chosen procedure for the determination of the radiance reference values has only limited influence on the cloud classification results, because the cloud classification results also depend on the choice of the threshold values. And both steps are directly interconnected; in the case that the radiance reference value was determined too high, the corresponding threshold values will be also increased and thus the effects on the cloud classification results mainly cancel out. 


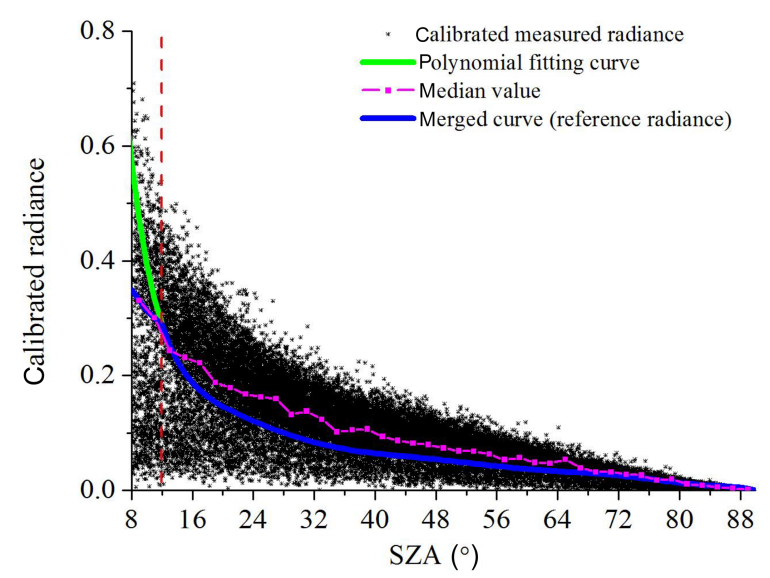

Figure 5. Calibrated measured zenith radiances at $380 \mathrm{~nm}$ (black points) extracted from all measurements for zenith view in the whole period. The blue curve represents a merged clear sky reference values over the whole SZA range $\left(8-90^{\circ}\right)$ : above $81^{\circ}$ it is based on radiative simulation results; between 12 and $81^{\circ}$ it represents a polynomial fit to the clear sky measurements shown in Fig. 8 b; below $12^{\circ}$ it is determined by calculating the median value of the measured radiance (see text). The green curve represents the extension of the polynomial fit to $\mathrm{SZA}<12^{\circ}$. The magenta curve represents the median values of the measured radiance. The red dashed line presents the SZA of $12^{\circ}$.

\subsection{2 $\mathrm{O}_{4}$ absorption}

The details of the $\mathrm{O}_{4}$ analysis are described in the Supplement. Thus here only a brief summary of the most important findings is given. Like in Wagner et al. (2014), the whole time series was analyzed using a fixed Fraunhofer reference spectrum (FRS). However, it turned out that by using a fixed FRS the $\mathrm{O}_{4}$ analysis was strongly affected by variations of the instrument slit function. Thus it was not possible to use the $\mathrm{O}_{4} \mathrm{SCD}$ derived from zenith observations for the detection of optically thick clouds. Fortunately, the lack of these $\mathrm{O}_{4}$ data did not strongly influence our classification results, because optically thick clouds are also well identified by (low values of) the observed zenith radiance. Fortunately, the determination of the spread of the $\mathrm{O}_{4}$ absorption for individual elevation sequences is almost not affected by this problem. Thus the spread of the $\mathrm{O}_{4}$ absorption could be still used for the detection of fog.

To make the measured $\mathrm{O}_{4}$ absorptions directly comparable to the simulations from RTM, the $\mathrm{O}_{4}$ SCDs were converted into the corresponding $\mathrm{O}_{4}$ air mass factors (AMF) by dividing the SCD by the $\mathrm{O}_{4}$ vertical column density (VCD, the vertically integrated concentration) (Solomon et al., 1987):

$\mathrm{AMF}=\frac{\mathrm{SCD}}{\mathrm{VCD}}$.

For the $\mathrm{VCD}_{\mathrm{O}_{4}}$ we used a value of $1.25 \times 10^{43}$ molecules $^{2} \mathrm{~cm}^{-5}$ (see Supplement). Since the FRS used in our analysis also contains atmospheric $\mathrm{O}_{4}$ absorption, the result of the DOAS fit actually represent the differences between the $\mathrm{O}_{4}$ SCDs of the FRS and the measured spectrum. This difference is usually referred to as differential SCDs (dSCD). Like the $\mathrm{O}_{4}$ SCDs (Eq. 3), the $\mathrm{O}_{4}$ dSCD can also be converted into the corresponding $\mathrm{O}_{4}$ dAMF:

$\mathrm{dAMF}_{\mathrm{O}_{4}}=\frac{\mathrm{dSCD} \mathrm{O}_{4}}{\mathrm{VCD}_{\mathrm{O}_{4}}}$.

Like in Wagner et al. (2014), the spread of the $\mathrm{O}_{4}$ absorption for individual elevation sequences is expressed as the spread of the corresponding $\mathrm{O}_{4}$ dAMFs.

\subsection{The scheme of the classification of sky conditions}

Wagner et al. (2014) investigated the sensitivity of several quantities, listed in Table 1, derived from MAX-DOAS observations to the presence and properties of clouds and aerosols and proposed a cloud classification scheme. From this scheme, in addition to the identification of clear and cloudy skies, further parameters like high and low aerosol optical depth (AOD), optically thin or thick clouds, continuous or broken clouds, or fog can be retrieved. The determination criteria of both the schemes introduced in this paper and in Wagner et al. (2014) are presented in Table 2.

\subsubsection{General principles and construction of the classification scheme}

The classification scheme is based on the CI, radiance and $\mathrm{O}_{4}$ absorption derived from MAX-DOAS as described in Sect. 2.2. Wagner et al. (2014) did sensitivity studies of the quantities with respect to the properties of clouds and aerosols. The basic classification results are derived from the retrieved CI for zenith observations; compared to clear sky conditions, the $\mathrm{CI}$ is systematically decreased in the presence of clouds. Also the temporal variation of the $\mathrm{CI}$ is investigated, because in the presence of clouds, usually substantial temporal variations of the CI occur. They can be quantified by the so-called temporal smoothness indicator (TSI), the discretized second derivative in time:

$\mathrm{TSI}_{y, n}=2 \cdot\left[\frac{\Delta t_{1} y_{n+1}+\Delta t_{2} y_{n-1}}{\Delta t_{1} \Delta t_{2} \cdot\left(\Delta t_{1}+\Delta t_{2}\right)}-\frac{y_{n}}{\Delta t_{1} \Delta t_{2}}\right]$.

Here $y$ is the $\mathrm{CI}$ and $n$ indicates the number of the selected elevation sequence, $\Delta t_{1}$ and $\Delta t_{2}$ are the time steps between measurement sequences $n-1$ and $n, n$ and $n+1$, respectively. The TSI can be calculated for all elevation angles separately. In this study, $\mathrm{TSI}_{\mathrm{z}}$ refers to the TSI for the measurements in zenith view, and TSI $I_{L}$ to the sum of the TSI for all non-zenith elevation angles. Here it should be noted that the typical time for a full elevation sequence is about $12 \mathrm{~min}$. If the cloud cover above the instrument changes on shorter timescales, most of these variations will be missed; thus in particular, small clouds and also small cloud holes might be missed by our classification scheme. 
Table 1. Quantities derived from MAX-DOAS observations for cloud classification, their abbreviations and thresholds. The superscript $n$ means normalized quantity. The subscripts $\mathrm{z}$ and $\mathrm{L}$ indicate zenith and off-zenith views, respectively.

\begin{tabular}{llrr}
\hline Quantity for cloud classification & Abbreviation & Threshold & $\begin{array}{r}\text { Threshold } \\
\text { (Wagner et al., 2014) }\end{array}$ \\
\hline $\begin{array}{l}\text { Normalized CI (340/420 nm) for } \\
\text { zenith view }\end{array}$ & $\mathrm{CI}_{\mathrm{z}}^{n}$ & 0.84 & 0.65 \\
$\begin{array}{l}\text { Temporal smoothness indicator } \\
\text { of the normalized CI for zenith view }\end{array}$ & $\mathrm{TSI}_{\mathrm{Z}}^{n}$ & $8 \times 10^{-8} \mathrm{~s}^{-2}$ & $1.2 \times 10^{-7} \mathrm{~s}^{-2}$ \\
$\begin{array}{l}\text { Sum of the temporal smoothness } \\
\text { indicator of the normalized }\end{array}$ & $\mathrm{TSI}_{\mathrm{L}}^{n}$ & $2.5 \times 10^{-7}$ & $3.3 \times 10-7$ \\
$\begin{array}{l}\mathrm{C} \text { in one scan } \\
\text { spread of the CI (without normalization) }\end{array}$ & $\mathrm{Sp}_{\mathrm{CI}}$ & & \\
$\begin{array}{l}\text { Normalized radiance at 380 nm } \\
\text { for zenith view } \\
\text { spread of the } \mathrm{O}_{4} \text { dAMF }\end{array}$ & $R_{\mathrm{Z}}^{n}$ & 0.3 & 0.14 \\
\hline & $\mathrm{Sp}_{4}$ & 0.94 & 0.9 \\
\hline
\end{tabular}

Table 2. Conditions used for the cloud classification scheme for MAX-DOAS observations at Wuxi. The abbreviations of the quantities are the same as in Table 1.

\begin{tabular}{|c|c|c|}
\hline Sky condition & Determination criteria & $\begin{array}{l}\text { Determination criteria } \\
\text { (Wagner et al., 2014) }\end{array}$ \\
\hline Clear sky with low aerosol load & high $\mathrm{Cl}_{\mathrm{z}}^{n} \&$ low $\mathrm{TSI}_{\mathrm{z}}^{n} \&$ low $\mathrm{TSI}_{\mathrm{L}}^{n} \&$ high $\mathrm{Sp}_{\mathrm{CI}}$ & high $\mathrm{CI}_{\mathrm{z}}^{n} \&$ low $\mathrm{TSI}_{\mathrm{z}}^{n}$ \\
\hline Extremely high midday CI & $\mathrm{CI}_{\mathrm{z}}^{n}$ larger than $1.3 \&$ high $\mathrm{Sp}_{\mathrm{CI}} \&$ low $R_{\mathrm{z}}^{n}$ & none \\
\hline Clear sky with high aerosol load & low $\mathrm{CI}_{\mathrm{z}}^{n} \&$ low $\mathrm{TSI}_{\mathrm{z}}^{n} \&$ low $\mathrm{TSI}_{\mathrm{L}}^{n} \&$ high $\mathrm{Sp}_{\mathrm{CI}}$ & low $\mathrm{CI}_{\mathrm{z}}^{n} \&$ low $\mathrm{TSI}_{\mathrm{z}}^{n} \&$ high $\mathrm{Sp}_{\mathrm{CI}}$ \\
\hline Cloud holes (zenith) & $\operatorname{high} \mathrm{CI}_{\mathrm{z}}^{n} \&$ high $\mathrm{TSI}_{\mathrm{z}}^{n}$ & $\operatorname{high} \mathrm{CI}_{\mathrm{z}}^{n} \& \operatorname{high} \mathrm{TSI}_{\mathrm{z}}^{n}$ \\
\hline Cloud holes (low elevation) & high $\mathrm{CI}_{\mathrm{z}}^{n} \&$ low $\mathrm{TSI}_{\mathrm{z}}^{n} \&$ high $\mathrm{TSI}_{\mathrm{L}}^{n}$ & $\operatorname{high} \mathrm{CI}_{\mathrm{z}}^{n} \& \operatorname{high} \mathrm{TSI}_{\mathrm{L}}^{n}$ \\
\hline Broken clouds & low $\mathrm{CI}_{\mathrm{z}}^{n} \&$ high $\mathrm{TSI}_{\mathrm{z}}^{n}$ or high $\mathrm{TSI}_{\mathrm{L}}^{n}$ & low $\mathrm{CI}_{\mathrm{z}}^{n} \&$ high $\mathrm{TSI}_{\mathrm{z}}^{n}$ \\
\hline Continuous clouds (large SZA) & low $\mathrm{CI}_{\mathrm{z}}^{n} \&$ low $\mathrm{TSI}_{\mathrm{z}}^{n} \&$ low $\mathrm{TSI}_{\mathrm{L}}^{n} \&$ low $\mathrm{Sp}_{\mathrm{CI}}$ & low $\mathrm{CI}_{\mathrm{z}}^{n} \&$ low $\mathrm{TSI}_{\mathrm{z}}^{n} \&$ low $\mathrm{Sp}_{\mathrm{CI}}$ \\
\hline Continuous clouds (small SZA) & high $\mathrm{CI}_{\mathrm{z}}^{n} \&$ low $\mathrm{TSI}_{\mathrm{z}}^{n} \&$ low $\mathrm{TSI}_{\mathrm{L}}^{n} \&$ low $\mathrm{Sp}_{\mathrm{CI}}$ & none \\
\hline Fog & low $\mathrm{CI}_{\mathrm{z}}^{n}$ \& low $\mathrm{Sp}_{4}$ & low $\mathrm{CI}_{\mathrm{z}}^{n}$ \& low $\mathrm{Sp}_{4}$ \\
\hline Optically thick clouds & (low $\mathrm{Cl}_{\mathrm{Z}}^{n}$ or continuous clouds for small SZA ) \& low $R_{\mathrm{Z}}^{n}$ & $\begin{array}{l}\text { low } \mathrm{CI}_{\mathrm{z}}^{n} \& \text { low } R_{\mathrm{Z}}^{n} \\
\text { or high } \mathrm{O}_{4} \mathrm{AMF}\end{array}$ \\
\hline
\end{tabular}

The spread of the CI for different elevation angles is also investigated. In the presence of clouds, similar CI values are usually found for all elevation angles, whereas for clear sky conditions, the CI values for different elevation angles differ significantly. The spread is quantified by the difference between the maximum and minimum CI for all elevation angles in one elevation sequence.

In addition to the $\mathrm{CI}$, the $\mathrm{O}_{4}$ absorption (expressed as $\mathrm{O}_{4}$ dAMF; see Eq. 4) is investigated. The $\mathrm{O}_{4} \mathrm{dAMF}$ for zenith observation increases strongly in the presence of optically thick clouds. In addition, similar $\mathrm{O}_{4}$ absorption values for different elevation angles are usually found in the presence of fog.

The measured radiance is used in the cloud classification scheme for the identification of optically thick clouds. While optically thin clouds cause an increased radiance, in the presence of optically thick clouds the radiance is largely reduced.

All quantities used in this study and their acronyms are listed in Table 1. The determination criteria of the classification scheme are shown in Table 2. Most sky conditions are exclusive, which means that only one condition can be fulfilled at a given time; we refer to them in the following as primary sky conditions. Other conditions like "fog" and "optically thick clouds" indicate additional information, and are referred to as secondary sky conditions. In Table 2, the symbol " $\&$ " requires that two criteria are simultaneously fulfilled, whereas "or" means that at least one of both criteria are fulfilled. 


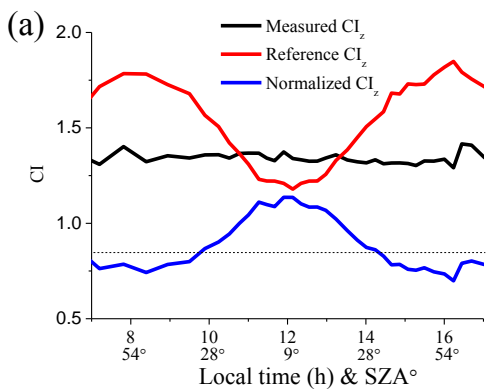

(b)

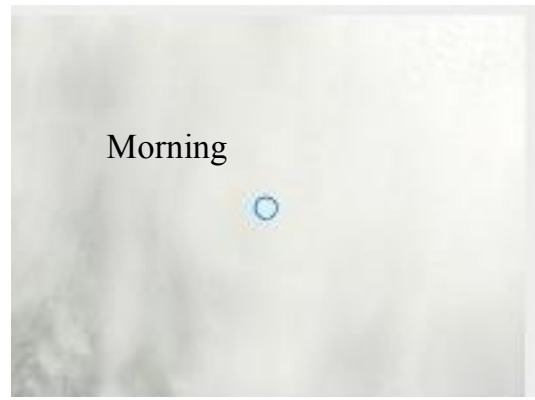

(c)

Afternoon

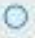

Figure 6. (a) The black, red and blue curves indicate the time series of the measured zenith $\mathrm{CI}_{\mathrm{z}}$, the corresponding reference $\mathrm{CI}_{\mathrm{z}}$ and the normalized $\mathrm{CI}_{\mathrm{z}}$, respectively, on 8 July 2012. The dashed line presents the threshold of normalized CI of 0.84 . The visual images in the morning (b) and in the afternoon (c) from MODIS indicate cloudy skies over the Wuxi site on the day.

\subsubsection{Description of the adapted scheme}

The classification scheme used in this study is basically identical to the original algorithm presented by Wagner et al. (2014). However, there are a few changes which are briefly described below.

a. The thresholds of the different quantities, used for the cloud classification, listed in Table 1, are adapted to the specific properties of the MAX-DOAS instrument in Wuxi. A detailed description of the procedure of the selection of thresholds can be found in the Supplement. Because of the instrument-specific response to the spectral radiance, new clear sky reference values of $\mathrm{CI}$ and radiances had to be determined (see Sect. 2.2.1). Consequently, also new threshold values for $\mathrm{CI}$ and radiance had to be determined. In addition, the threshold values of $\mathrm{TSI}_{\mathrm{z}}, \mathrm{TSI}_{\mathrm{L}}$ and spread of CI had to be adapted due to the instrument-specific measurement duration and set of elevation angles. Here it should be noted that the determination of threshold values is a fundamental necessity for each new instrument, and depends also on the atmospheric conditions and availability of coincident measurements of aerosol properties (e.g., from sun photometers). In Table 1, our threshold values are compared to those used in Wagner et al. (2014).

b. Compared to Cabauw, Wuxi is located at lower latitudes, and consequently much smaller SZA occur during the course of the year. Thus the calibration and normalization of the radiance is extended to the lower boundary of an SZA of $10^{\circ}$ (see Sect. 2.2.1). Moreover, the occurrence of low SZA also led to the definition of two additional sky conditions (Table 2). First, we found that at small SZA the identification of cloudy conditions based on zenith measurements of the CI, especially in the case of continuous clouds, is no longer possible. Thus, for low SZA the feature of a nearly constant CI (small spread of the CI) for the different elevation angles is used as the dominant criterion for the identifica- tion of continuous clouds. This additional sky condition is referred to as "continuous clouds" (see Sect. 2.3.3).

Second, we refer to a rare sky condition at low SZA as "extremely high midday CI" (see Sect. 2.3.4). These observations are characterized by temporarily strongly increased CI values (strong reduction of the visible radiance), the origin of which we can only speculate upon. A more detailed description of these cases appears in Sect. 2.3.4.

c. As outlined above, in this study we only consider the spread of the $\mathrm{O}_{4}$ dAMF (difference between the maximum and minimum values of the dAMFs in an elevation sequence) to identify the presence of fog. We did not use the $\mathrm{O}_{4}$ absorption for the detection of optically thick clouds, but rather detected them using the measured radiance (see Sect. 2.2.2 and Table 2).

In principle the classification scheme can be applied to any other MAX-DOAS measurements covering the same spectral range. For the calibration of the zenith radiance and CI as well as the determination of the threshold values, the measurement period should cover a variety of different sky conditions, especially including days with clear skies and low aerosol load. For these clear days independent information on the AOD (e.g., from sun photometers or satellite observations) should also be available. The comparison of the MAXDOAS results with the AOD measurements allows in particular the threshold value for the CI to be adjusted to achieve a meaningful separation of clear sky conditions with either low or high aerosol loads (see Sect. 3.1.1).

\subsubsection{Continuous clouds for small SZA}

In Fig. 6a CI values for 8 July 2012 are presented. Besides the original CI (black line), also the reference values for clear sky (red line) and the normalized CI (blue line) are shown. Around noon, the original CI values are found to be higher than the clear sky reference values. Thus the normalized CI shows a maximum around noon, which even exceeds the 
8 July 2012, "Continuous clouds (small SZA)"
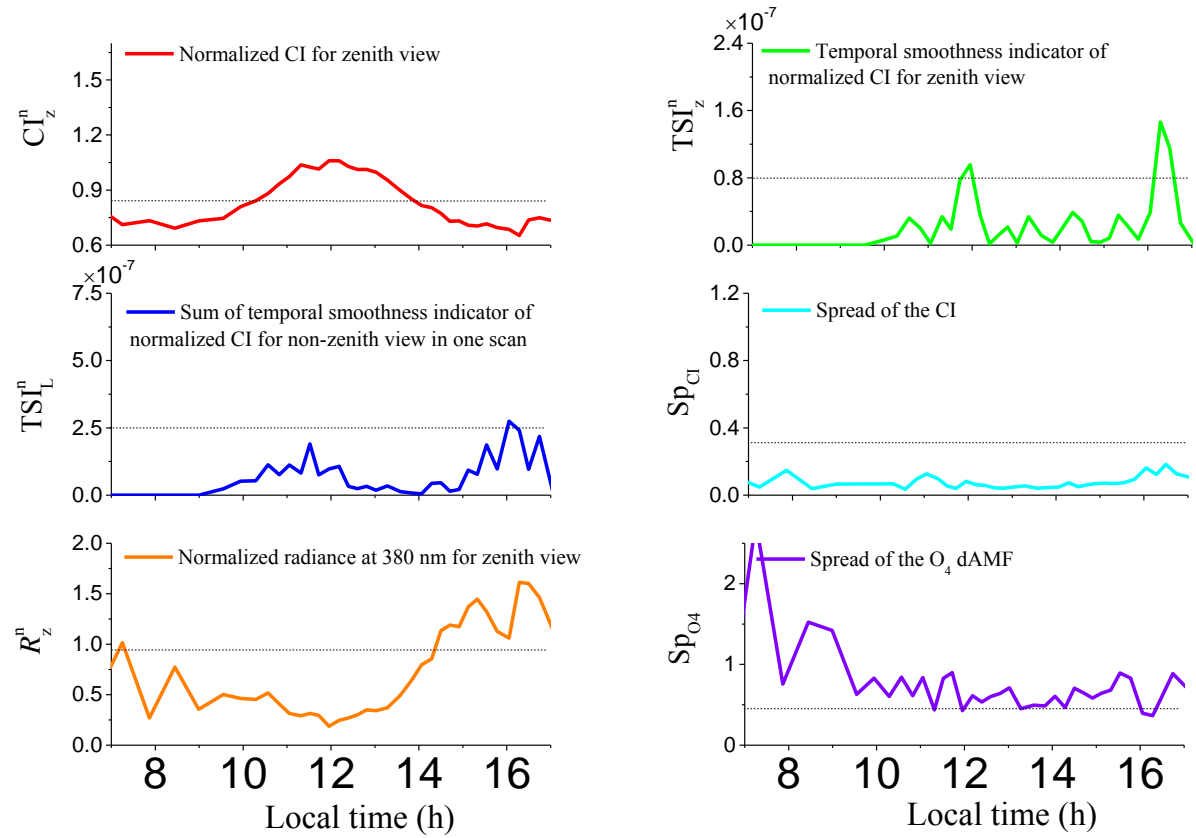

Figure 7. Time series of the quantities (same as in Table 1) derived from MAX-DOAS for 8 July 2012, categorized as "continuous clouds (small SZA)". The dashed line presents the thresholds of each quantity. The normalized CI (top left) is the same as in Fig. 6.

threshold value for clear sky (see Table 1), and consequently the measurements around noon (from 10:00 to 14:00 local time (LT) with SZA smaller than $30^{\circ}$ ) would be classified as clear sky conditions with low aerosol load by the scheme in Wagner et al. (2014). In contrast to this assignment, the MODIS true color images in Fig. 6b and c clearly indicate that on 8 July 2012 clouds were present. Also the normalized radiance and the spread of the CI (Fig. 7) indicate the presence of (optically thick) clouds. This apparent contradiction points to a fundamental problem of the use of the CI for the discrimination between clear and cloudy conditions at small SZA (about $<35^{\circ}$, see Fig. 6a). Thus for such SZA an additional indicator is needed to detect the presence of continuous clouds.

Fortunately, the spread of the CI for the different elevation angles $\left(\operatorname{spread}_{\mathrm{CI}}\right)$ can be used for that purpose. In Fig. 7, it is shown that during the whole day, spread $_{\mathrm{CI}}$ is lower than its threshold, indicating the presence of continuous clouds. Whenever such a situation is encountered, the sky condition is denoted as "continuous clouds (small SZA)" to separate it from the "regular" continuous cloud detection, which is denoted as "continuous clouds (large SZA)".

\subsubsection{Exceptional case: extremely high midday CI}

On six days, all classified as "clear sky with low aerosol load", another interesting phenomenon was found at low SZA: in the course of the day, the normalized CI increases until it peaks far above the threshold between 13:00 and
14:00 (LT), whereas the normalized radiance drops below the threshold. In contrast to the findings for continuous clouds at small SZA, the spread of the CI remains above the threshold (see results for 29 July 2012, Fig. 8). The latter finding clearly indicates that no continuous clouds were present on that day. This conclusion is confirmed by the MODIS true color images (Fig. 9a), where no clouds can be seen. In Fig. 9b two measured radiance spectra for similar SZA (about $20^{\circ}$ ) and their ratio are shown. At wavelengths larger than $330 \mathrm{~nm}$, much lower intensities are measured in the afternoon (red spectrum) than in the morning (black), and the ratio between both spectra depends linearly on wavelength, decreasing from 1 at about $320 \mathrm{~nm}$ to 0.7 at $420 \mathrm{~nm}$. At the time of writing, we can only speculate on the causes of this phenomenon. We focus on three possible explanations.

1. The findings are artifacts related to measurement geometry. The fact that this exceptional case was only encountered in summer and only within a small time range (13:00-14:00 LT) suggests an influence of SZA, perhaps similar to the case found for continuous clouds at very small SZA. However, the peak in CI and corresponding dip in normalized radiance do not occur at the smallest SZA.

2. The results are caused by instrumental errors. Specular reflection on an object within the field of view of the instrument or other short-time disturbances to the instrument (heating, interference with other electronic 
29 July 2012, "Extremely high midday CI"
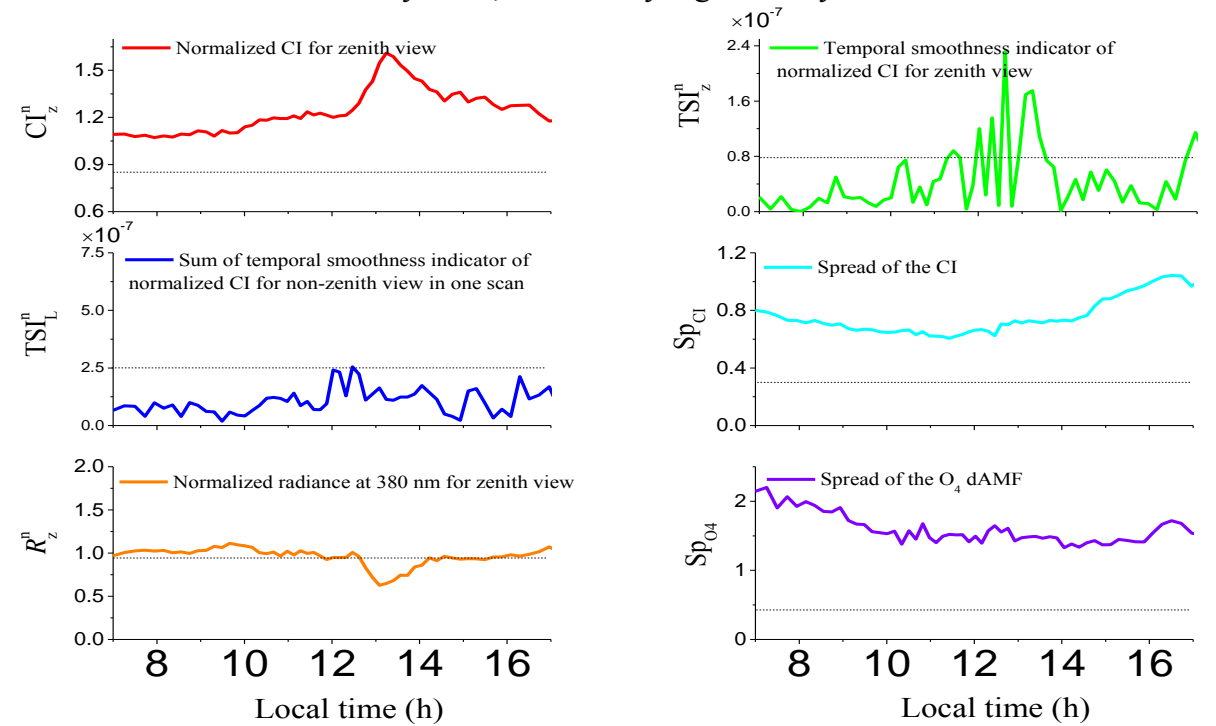

Figure 8. Time series of the quantities (same as in Table 1) derived from the MAX-DOAS cloud classification scheme on 29 July 2012 , categorized as "extremely high midday CI". The dashed line presents the thresholds of each quantity. As indicated in Fig. 9, this day was completely cloudy over Wuxi.

(a)

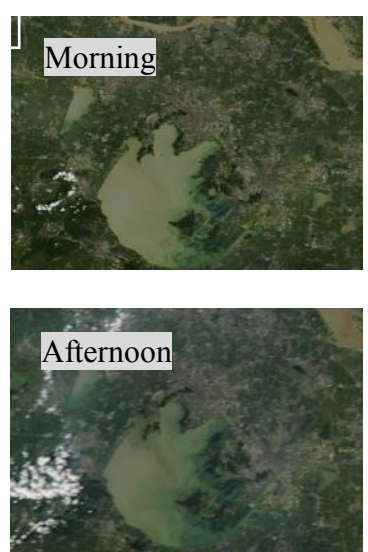

(b)

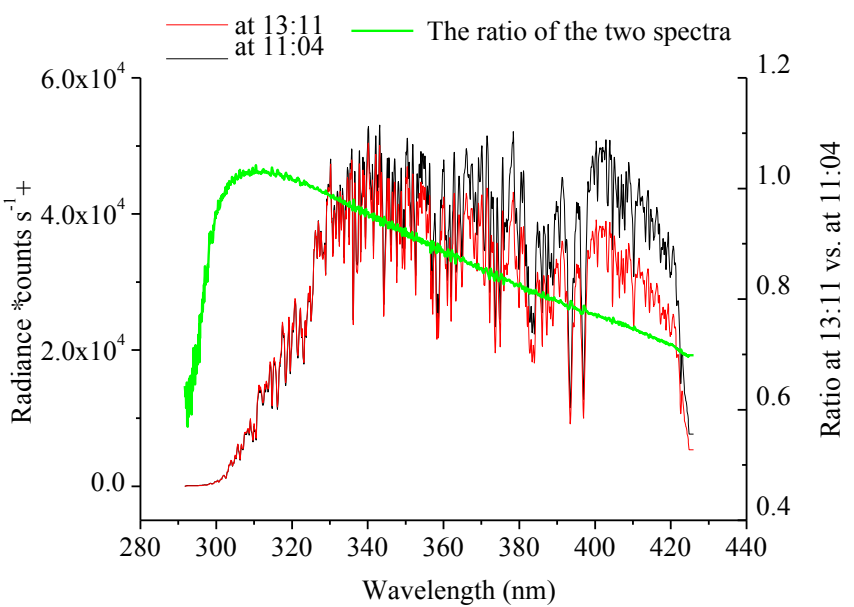

Figure 9. Panel (a) shows visual images of MODIS on 29 July 2012 with the sky condition of extremely high midday CI; (b) zenith spectra in the morning (black) and afternoon (red) measured at a SZA of $20^{\circ}$. The green curve indicates the ratio of the spectrum in the morning compared to in the afternoon.

equipment) cannot be excluded; but we have no specific evidence for this possibility.

3. Since Wuxi is located close to a large lake (Taihu Lake), the scattering and reflection of the solar light at the water surface might affect the observed zenith radiance; but again, we have no specific evidence for this possibility.
4. We observe a real, physical phenomenon, e.g., the presence of aerosols that strongly absorb visible radiation. For all observed cases, MODIS Aqua (which passes over Wuxi at the time of the CI peak occurrence) detects small AOD of 0.3-0.6. If these aerosols strongly absorb visible radiation, the measured spectrum may be affected in the way we observe (Fig. 9b). This assumed aerosol plume is probably a local phenomenon (judging by the relatively short CI peak), as no obvious 
changes in aerosol load or composition were detected at the Taihu AERONET station. It is, however, unclear which type of aerosol could induce this type of behavior; we were not able to model it.

Despite the fact that we are currently unable to explain our findings, we included the exceptional case of extremely high midday CI into our cloud classification scheme so that it may be investigated in more detail in the future. Note, however, that this is a rather rare phenomenon.

\subsection{Independent data sets for the comparison with MAX-DOAS}

\subsubsection{AERONET AOD and visibility meter}

We acquired the AOD and Angström Parameter from the level 1.0 and 1.5 data set of the AERONET sun photometer (http://aeronet.gsfc.nasa.gov/) (Holben et al., 1998, 2001) operated in Taihu, China $\left(31.42^{\circ} \mathrm{N}, 120.22^{\circ} \mathrm{E} ; 20 \mathrm{~m}\right.$ a.s.l.). The Taihu site is located about $18 \mathrm{~km}$ southwest of the Wuxi MAX-DOAS site. The typical integration time of the sun photometer is 2 to $15 \mathrm{~min}$, well matching the temporal resolution of the MAX-DOAS instrument. Note that the level 1.0 data set is not filtered by a cloud screening procedure. Thus the AOD in the data set is actually the ensemble optical depth of clouds and aerosols. An automatic cloud screening scheme is applied to the level 1.0 data to yield the largely cloud-cleared level 1.5 data set (Smirnov et al., 2000).

A forward-scattering visibility meter (Manufacturer: Anhui Landun Photoelectron Co. Ltd. Model: DNQ2 forwardscattering visibility meter) was operated near the MAXDOAS instrument at the Wuxi site. This visibility meter automatically measures the visibility at $550 \mathrm{~nm}$ derived from the forward-scattered signal of a light-emitting diode at $950 \mathrm{~nm}$ using an empirical conversion formula (Nebuloni, 2005).

\subsubsection{OMI and GOME-2 cloud products}

The OMI (Levelt et al., 2006a, b) aboard the EOS Aura satellite achieves daily global coverage. Its spatial resolution is $24 \times 13 \mathrm{~km}^{2}$ in nadir, and increases to $68 \times 14 \mathrm{~km}^{2}$ at the swath edges (disregarding the outer 5 pixels). The OMI overpass above the Wuxi site is between 13:00 and 14:00 LT. Effective cloud fraction (CF) and cloud top pressure (CP) retrieved from OMI are extracted from OMCLDO2 product, DOMINO version 2.0 (Acarreta et al., 2004; Sneep et al., 2008) obtained from the Tropospheric Emission Monitoring Internet Service (TEMIS) (http://www.temis.nl). The cloud products from OMI are retrieved using the $\mathrm{O}_{4}$ absorption band at $477 \mathrm{~nm}$. The effective $\mathrm{CF}$ is the cloud fraction of a Lambertian cloud with albedo 0.8, yielding the same top-of-atmosphere (TOA) radiance as the real cloud in the scene (Stammes et al., 2008). For the comparisons with the MAX-DOAS results, only data for satellite ground pixel centers with a distance less than $0.1^{\circ}$ latitude and $0.1^{\circ}$ longitude from the Wuxi site are included. In addition, the observations of the outermost pixels (i.e., pixel numbers 1-10 and 5160 ) or pixels where a "row anomaly" had been reported (see http://www.temis.nl/airpollution/no2col/warning.html) were removed before the comparison (see also Ma et al., 2013).

The Meteorological Operational Satellite platform (METOP-A) was launched in October 2006 in a sunsynchronous polar orbit with an equator crossing time of 09:30 LT. It carries the GOME-2 (Callies et al., 2000; Munro et al., 2006, 2015) with a spatial resolution of $80 \times 40 \mathrm{~km}^{2}$ and a global coverage in 1.5 days. We obtained the effective $\mathrm{CF}$ and the $\mathrm{CP}$ from the daily level 2 products of the TM4NO2A version 2.3 (Boersma et al., 2004, 2007) from the TEMIS website. The effective CF and the CP are retrieved by the improved Fast Retrieval Scheme for Clouds from the Oxygen A-band algorithm (FRESCO+) (Wang et al., 2008) based on the measurements of the oxygen A-band around $760 \mathrm{~nm}$. Considering the rather coarse spatial resolution of GOME-2, to keep as much data as possible, the selection criterion was extended to a distance within $0.2^{\circ}$ latitude and $0.2^{\circ}$ longitude from the Wuxi site.

\subsubsection{Images, aerosol and cloud products from MODIS}

Two MODIS instruments are operated on the Terra and Aqua satellites. They provide radiance images from which various products can be retrieved. In this study we use operational level 2 cloud products (Baum and Platnick, 2006). Terra and Aqua operate in polar sun-synchronous orbits at $705 \mathrm{~km}$ above the Earth's surface with a daytime equator crossing at 10:30 and 13:30 LT, respectively. Considering that the MAXDOAS measurements are only analyzed for daytime, we just extracted daytime cloud products from MODIS.

Two MODIS aerosol product clusters (MOD04_L2 from Terra and MYD04_L2 from Aqua) and two MODIS Level 2 cloud product clusters (MOD06_L2 from the Terra platform and MYD06_L2 from the Aqua platform) are acquired from collection 5.1 supplied by NASA (http://ladsweb.nascom. nasa.gov/data/search.html). We used the AOD at $550 \mathrm{~nm}$ with the spatial resolution of $10 \times 10 \mathrm{~km}^{2}$ from the scientific data set of "Optical_Depth_Land_And_Ocean", which has more stringent control; namely, it requires that the quality assurance confidence (QAC) flag be larger than 0 over land (see Levy et al., 2010; Remer et al., 2005). A technique known as $\mathrm{CO}_{2}$ slicing is used to deduce the $\mathrm{CP}$ and the geometrical $\mathrm{CF}$ from radiances measured in the spectral bands located within the broad $15 \mu \mathrm{m} \mathrm{CO}_{2}$ absorption region (Wielicki and Coakley, 1981) at $5 \mathrm{~km} \times 5 \mathrm{~km}$ resolution. The cloud optical thickness (COT) is retrieved by the solar reflectance technique at a visible wavelength (e.g., $0.65 \mu \mathrm{m})$ and a shortwave-infrared (SWIR) wavelength (e.g., 1.64 or $2.15 \mu \mathrm{m}$ ) based on the decision tree algorithm (Platnick et al., 2003; King et al., 2004). The COT is given at $1 \mathrm{~km} \times 1 \mathrm{~km}$ resolution. As for OMI, MODIS data with ground pixel centers within $0.1^{\circ}$ latitude 
and $0.1^{\circ}$ longitude from the Wuxi site are included for the comparison with MAX-DOAS.

In addition to the MODIS aerosol and cloud products, for selected case studies we also used true color images above Taihu (near the Wuxi site) with a spatial resolution of $250 \mathrm{~m}$ derived from both MODIS instruments. They were downloaded from the website of MODIS Rapid Response, NASA/GSFC (http://aeronet.gsfc.nasa.gov/cgi-bin/ bamgomas_interactive). The true color images give an intuitive view of the coverage and structure of the clouds and aerosols over Wuxi.

The effective CF from OMI and GOME-2 is not a geometrical $\mathrm{CF}$ as retrieved by MODIS, but it is a combination of geometric $\mathrm{CF}$, cloud reflectance and clear sky reflectance (see Eq. 6). To make the cloud products more comparable, we converted the MODIS level 2 cloud optical thickness $\left(\tau_{\mathrm{c}}\right)$, which is given at $650 \mathrm{~nm}$ (King et al., 1998), into an observed TOA cloud reflectance $R\left(\tau_{\mathrm{c}}\right)$, and computed the effective CF $\left(\mathrm{CF}_{\text {eff }}\right)$ from the cloud reflectance and geometric $\mathrm{CF}\left(\mathrm{CF}_{\text {geo }}\right)$ in a similar way as Stammes et al. (2008):

$\mathrm{CF}_{\text {eff }}=\mathrm{CF}_{\text {geo }} \frac{R\left(\tau_{\mathrm{c}}\right)-R_{\text {clear }}}{R_{\mathrm{alb}=0.8}-R_{\text {clear }}}$,

where $R_{\text {clear }}$ is the clear sky reflectance and $R_{\mathrm{alb}=0.8}$ is the reflectance of the clouds with cloud albedo of 0.8 . The relation of $R\left(\tau_{\mathrm{c}}\right)$ and COT is acquired by simulations using McArtim and is shown in Fig. S3 in the Supplement. Note that the occurrence of effective CF larger than 1 is possible due to the fact that cloud albedo may be larger than 0.8. (Stammes et al., 2008). However we set the effective CF from MODIS to 1 if the calculated effective $\mathrm{CF}$ is larger than 1 , because the effective CF from OMI and GOME-2 is also clipped between 0 and 1 (Wang et al., 2008).

\section{Results}

\subsection{Cloud classification results for 2.5 years of MAX-DOAS measurements}

The monthly mean relative frequency and monthly accumulated observation numbers of the different sky conditions from MAX-DOAS are shown in Fig. 10. Figure 10b indicates that more observations were made in summer because of the longer duration of the days and due to the shorter exposure time for individual measurements. The gap from 15 December 2012 to 28 February 2013 is caused by a temporal shutdown of the MAX-DOAS instrument. The short-term shutdowns in July and August, 2013 also affect the number of observations.

An obvious intra-annual variation of the frequencies of clear sky and cloudy conditions can be found in Fig. 10a. The frequency of the clear sky conditions is higher in winter than in summer, especially with high aerosol load. The frequency of cloudy skies is higher in summer than in winter, especially of continuous clouds. This annual variation of the cloud amount over the Yangtze River Delta, China, including Wuxi station, has been reported by Zhao et al. (2014). The continuous clouds (small SZA) only occur in summer, which is due to the fact that these are only found for small SZA (below about $35^{\circ}$, see Sect. 2.3.3). However, we cannot exclude the possibility that part of the seasonal variation might be caused by the dependence on SZA of the retrieved cloud sensitive parameters.

An overview on the relative fraction of occurrences of the different sky conditions for the complete measurement time series is presented in Fig. 11. Cloudy skies including continuous clouds (large SZA), continuous clouds (small SZA), "broken clouds" and "cloud holes" were present in the majority of measurements (about $80.4 \%$ ). Indeed broken clouds, cloud holes in zenith or off-zenith view and continuous clouds ("continuous clouds (high SZA)" and "continuous clouds (low SZA)") account for about 62, 31 and $27 \%$ of all cloudy skies, respectively. The category continuous clouds (small SZA) contributes only about $19 \%$ to the continuous clouds. The category of optically thick clouds accounts for $14.1 \%$ of the cloudy cases. Proportions of 50.0, 33.1 and $16.9 \%$ optically thick clouds are assigned to the sky conditions of continuous clouds (high SZA), continuous clouds (low SZA) and broken clouds, respectively. Clear skies including either low or high aerosol load were present in about $19 \%$ of all measurements. Extremely high midday CI was only present in $0.3 \%$ of all measurements. The remaining $25 \%$ of all measurements is classified as cloud holes in zenith or off-zenith view.

\subsubsection{Uncertainties of the classification method}

The MAX-DOAS cloud classification scheme is based on a set of thresholds for different quantities. When the values of the measured quantities fluctuate around these thresholds, the resulting sky conditions could be mixed with each other. This effect is referred to as the "edge effect", which is a wellknown problem of threshold-based classification schemes. In order to estimate the effect of the specific choices of the threshold values, we compared the cloud classification results for slight variations of the threshold values. In Fig.12 the classification results for the original set of thresholds as well as for the modified thresholds are shown (changed by $\pm 10 \%$.). For most of the quantities, only very small changes of the classification results for the modified threshold values are found. This indicates that for these quantities the exact choice of the threshold values is not critical. In contrast, for the CI the exact value of the threshold value has a significant impact on the classification results. In particular, it affects the assignment to either clear sky with low or high aerosol load. From the results shown in Fig. 12, we can, however, directly conclude that the original threshold value for the $\mathrm{CI}$ is probably a very reasonable choice. If e.g., a smaller threshold value was used, almost no measurements are assigned to the con- 

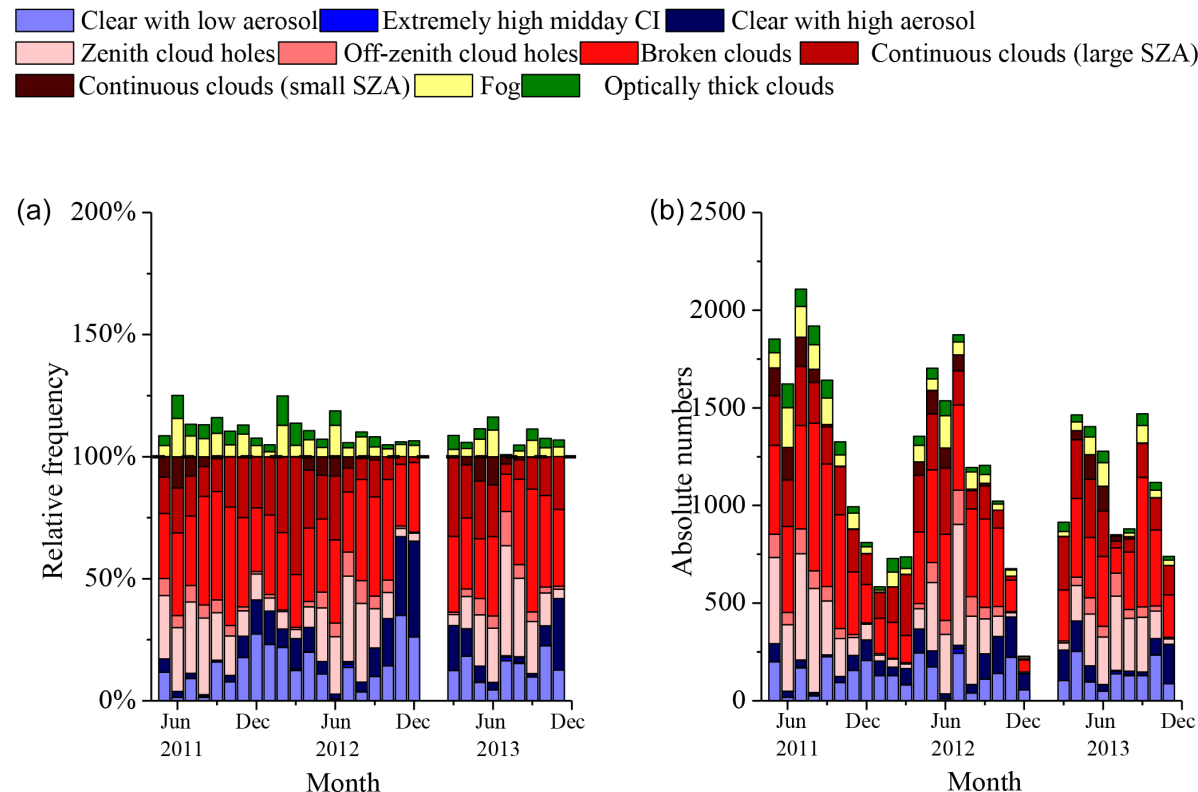

Figure 10. The monthly frequency distribution of the cloud classification scheme. (a) Relative frequencies of the different sky conditions (indicated by the different colors). Bars between 0 and $100 \%$ represent the frequency of the primary sky conditions; bars above $100 \%$ represent the frequency of the secondary sky conditions. The black dashed line emphasizes the $100 \%$ mark. (b) Accumulated absolute numbers of the sky conditions in each month.
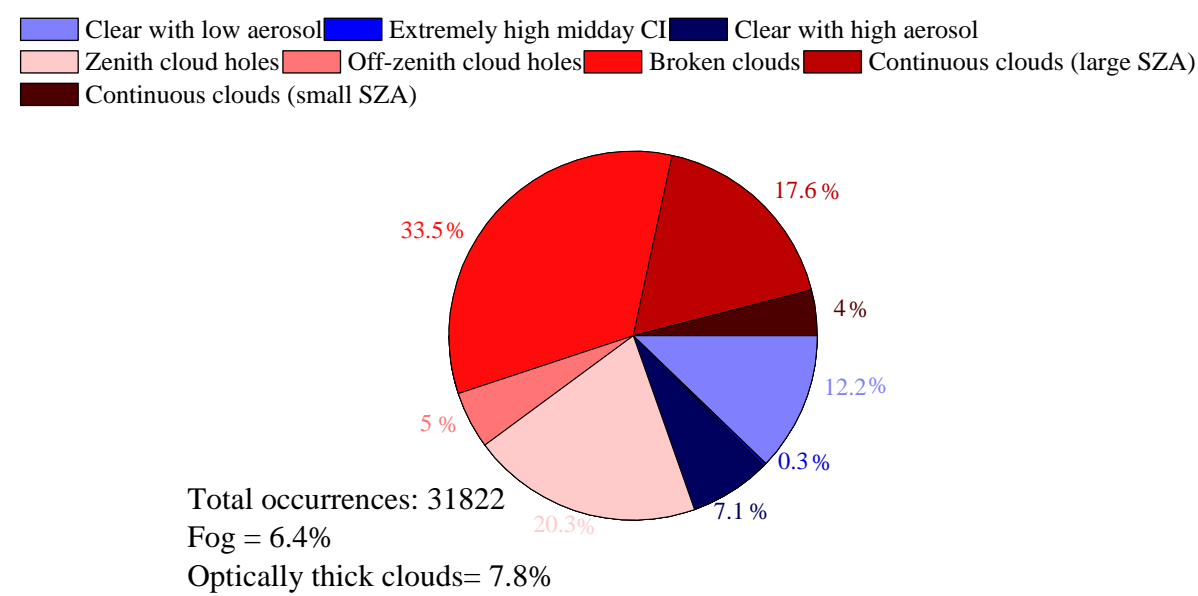

Figure 11. Relative fractions of the different sky conditions retrieved from the MAX-DOAS cloud classification scheme during the whole measurement period.

dition of clear sky with high aerosol load (see Fig. 12 top), which is in contradiction to the frequent occurrence of rather high AOD at the Wuxi site. The comparison with AERONET AOD observations also indicates that for the threshold value used, the transition between clear sky with either low or high aerosols corresponds to an AOD of about 0.5 , which is very reasonable. Also the assignment to either broken clouds or cloud holes is strongly affected by the chosen threshold for the CI. But this ambiguity is of minor importance, because both classifications results basically belong to the same cloud category.

\subsection{Comparison with coincident ground-based and satellite measurements}

In this section we compare the results of our cloud classification scheme for the whole time period with coincident data from the independent data sets (AOD from AERONET and MODIS, visibility from visibility meter and cloud products from MODIS, OMI and GOME-2). As pointed out in the introduction, no quantitative and direct comparison of the MAX-DOAS cloud classification results with the independent data sets is possible, because (a) the same quantities are 


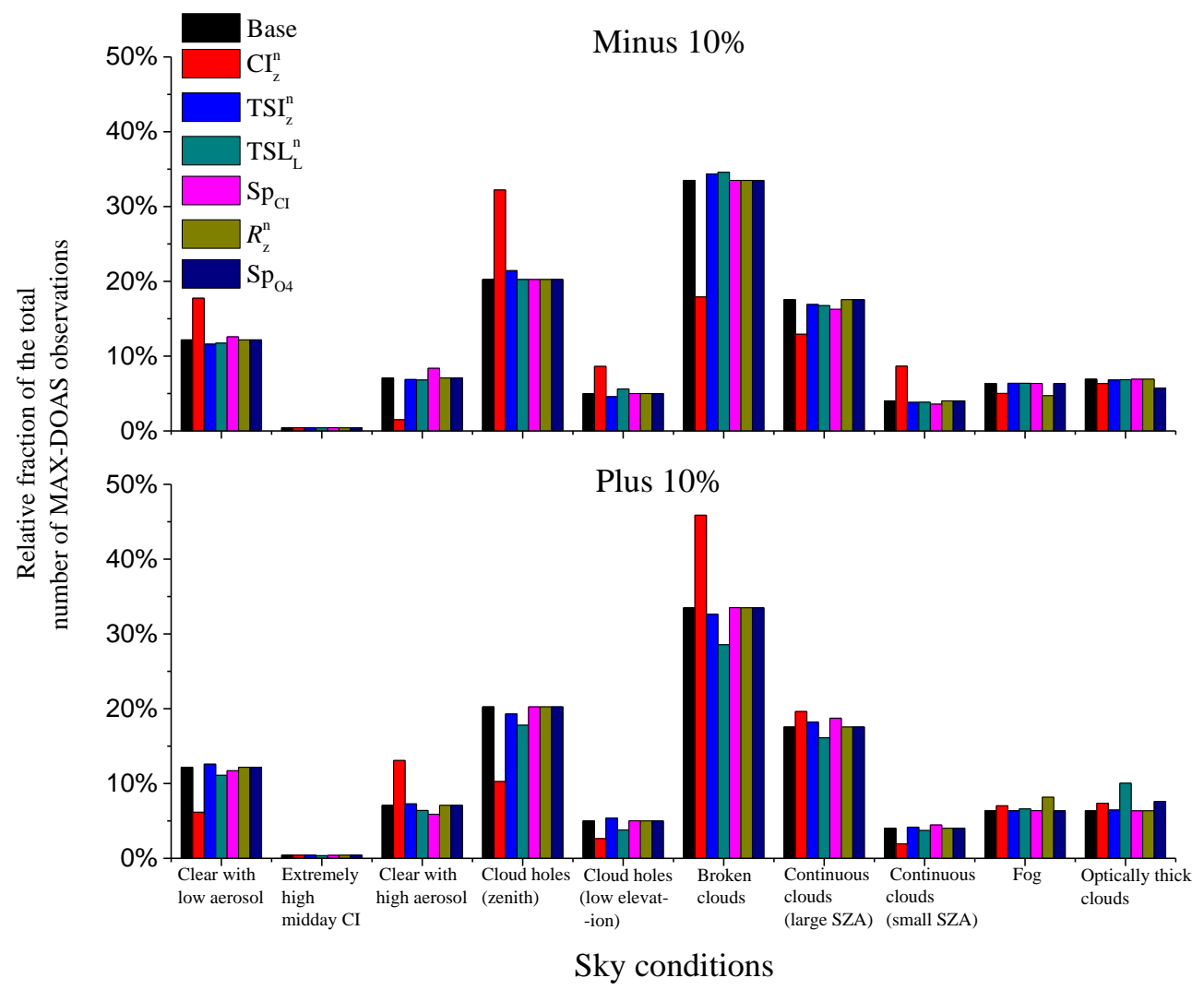

Figure 12. Results of the cloud classification scheme for slightly changed threshold values (top: $+10 \%$, bottom: $-10 \%$ ) for the individual measured quantities. The black columns show the results using the unchanged thresholds. The colored columns show the classification results if only one threshold value was changed (see legend).

not compared and (b) systematic differences in spatial and temporal coverage and resolution exist. Thus the comparison of our classification results to the independent data sets is performed in a semi-quantitative way. First we assign the MAX-DOAS results to each data point from the independent measurements, and then we determine the absolute numbers and the relative fractions of the individual sky conditions for different intervals of the quantities derived from the independent measurements.

\subsubsection{Comparison to AERONET AOD}

For the comparison to the AOD from AERONET, we selected AOD values with time differences $<15 \mathrm{~min}$ and assigned them to the MAX-DOAS results. In the left subfigures of Fig. 13a and b, the relative frequencies of the individual sky conditions (indicated by the different colors) are shown for different intervals of the simultaneously measured AOD. Note that the sky conditions displayed between 0 and $100 \%$ indicate the primary sky conditions; those displayed above $100 \%$ indicate the secondary sky conditions. In the right subfigures of Fig. 13a and b, the corresponding absolute numbers of the different sky conditions are shown.
Figure 13 shows that the number of measurements classified as clear sky with low aerosol load decreases with increasing AERONET AOD. The highest fractions of "clear sky with high aerosol load" are found for AOD between 0.5 and 1.5. These findings indicate that the discrimination between the sky conditions of clear sky with low or high aerosol is meaningful and can provide a first estimation of the AOD. From this comparison we can conclude in particular that for the selected threshold of the CI, the discrimination between low and high AOD corresponds to an AOD threshold of about 0.5 , which seems to be a very reasonable choice (see Sect. 3.1.1).

For days with AOD $<1$, if clouds are detected by MAXDOAS, they are classified as either cloud holes or broken clouds. With increasing AOD the number of measurements classified as cloudy increases and so does the fraction of continuous clouds and fog.

The two AERONET data sets show similar patterns, but level 1.0 data are more often classified as clouds than level 1.5 data, in accordance with the application of the AERONET cloud screening algorithm. As a consequence of cloud screening, the number of measurements is halved, and only a few points are left for the highest AOD bins. 

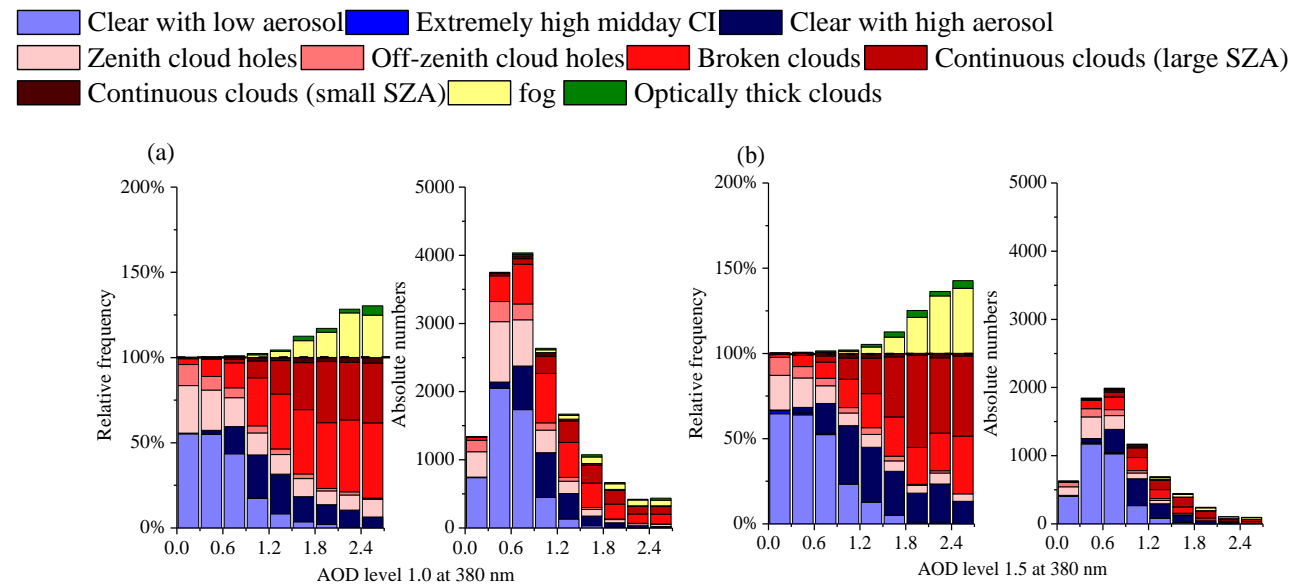

Figure 13. Results of the cloud classification scheme as a function of the AOD obtained from the AERONET measurements at Taihu. (a) The AODs are from the level 1.0 data sets without cloud-screening and (b) from automatically cloud-cleared level 1.5 data sets. In each subfigure, left: relative frequencies of the different sky conditions (see the caption of Fig. 10 and the text for details); right: absolute numbers of the sky conditions as a function of the AOD.

\subsubsection{Comparison to visibility meter}

The comparison of the MAX-DOAS results with the visibility meter results is shown in Fig. 14. As expected the frequency of fog is highest for the lowest visibility. Also the frequency of clear sky with high aerosol load is highest for visibilities below $20 \mathrm{~km}$. In contrast, the frequency of clear sky with low aerosol load is highest for the highest visibility values. The increasing fraction of continuous clouds and optically thick clouds with decreasing visibility might be caused by the occurrence of rain or possible factors which increase the probability of both aerosols and clouds (e.g., high humidity).

\subsubsection{Comparison to aerosol and cloud data from OMI, GOME-2 and MODIS}

In Figs. 15-18 the comparisons between the results from MAX-DOAS and the satellite instruments are shown. For these comparisons the MAX-DOAS results are averaged over $1 \mathrm{~h}$ around the respective satellite overpass times (see Sect. 2.4.2 and 2.4.3 for spatial collocation criteria).

In Fig. 15a and b the MAX-DOAS results are compared with the AOD at $550 \mathrm{~nm}$ from MODIS on Aqua and on Terra, respectively. Similar distributions of the relative frequencies of the sky conditions along the AOD from MODIS are found for both of the MODIS instruments. Note that because some strict cloud screening and quality assurance controlling schemes are applied to the MODIS AOD data sets, most of the cloud-contaminated data are discarded. The small number of measurements with AOD > 1.8 means that the relative frequencies of the sky conditions are probably not representative. The same is the case for the smallest AOD bin, although the reason for the small number of measurements is probably that cases of $\mathrm{AOD}<0.3$ are rare in the investigated region. Except for these rarely encountered cases, the features of the distributions of the sky conditions along the AOD are quite similar to the comparison with AERONET AOD data sets. The relative frequencies of the clear sky with low aerosol load sky condition decrease along with the increasing AOD. Most of the clear sky with high aerosol load sky conditions occur in the AOD between 0.6 and 1.2. The fact that cloudy cases are still found, despite the rigorous cloud screening by MODIS, may be attributed to the difference in air masses sensed by MODIS and MAX-DOAS due to imperfect collocation (see Sect. 3.2.4). It may, however, also be caused by incorrect classification by the MAX-DOAS algorithm. Overall the results from MAX-DOAS are mostly consistent with the AOD data from MODIS.

In Fig. 16a, b, c and d, the MAX-DOAS results are shown as functions of the effective CFs derived from OMI, GOME-2 and MODIS on Aqua and on Terra, respectively. The frequency of clear sky conditions (with either high or low aerosol load) is highest for small effective CFs. Two facts probably contribute to this finding. The first is the misclassification of aerosols as clouds by satellite instruments (see Sect. 3.2.5) and the second is the possibility of clouds being detected outside of the FOV of the MAX-DOAS instrument by satellite instruments (due to their different FOV and time difference). This aspect will be investigated in more detail in Sect. 3.2.4 for MODIS due to its relative fine spatial resolution (CF and CP: $5 \times 5 \mathrm{~km}^{2}$; COT: $1 \times 1 \mathrm{~km}^{2}$ ). The frequencies of continuous clouds and optically thick clouds are highest for large effective CFs. Broken clouds are most frequent for the effective CF between $10 \%$ and $70 \%$. Compared with other satellites, a higher frequency of fog is found for GOME-2, which can be explained by the higher probability for fog at the earlier overpass time of GOME-2 (09:30 LT) compared to OMI (13:30 LT). The similar, but smaller, dif- 
Clear with low aerosol $\square$ Extremely high midday CI $\square$ Clear with high aerosol

Zenith cloud holes $\square$ Off-zenith cloud holes $\square$ Broken clouds $\square$ Continuous clouds (large SZA)

Continuous clouds (small SZA) $\square$ Fog $\square$ Optically thick clouds

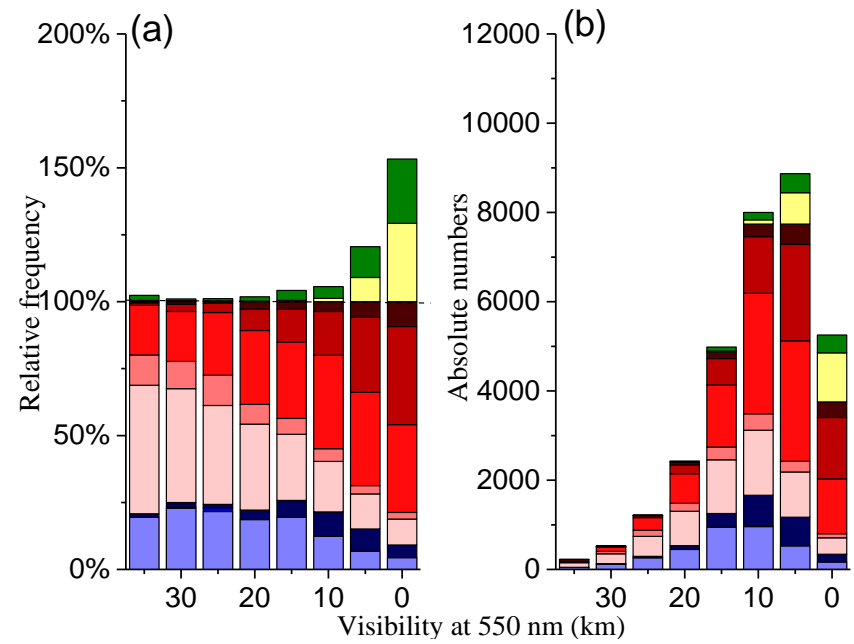

Figure 14. Results of the cloud classification scheme as a function of the visibility at $550 \mathrm{~nm}$ obtained from the visibility meter. (a) Relative frequencies of the different sky conditions (see the caption of Fig. 10). (b) Absolute numbers of the sky conditions as a function of the visibility.

Clear with low aerosol $\square$ Extremely high midday CI $\square$ Clear with high aerosol

Zenith cloud holes $\square$ Off-zenith cloud holes $\square$ Broken clouds $\square$ Continuous clouds (large SZA)

Continuous clouds (small SZA) $\square$ Fog $\square$ Optically thick clouds
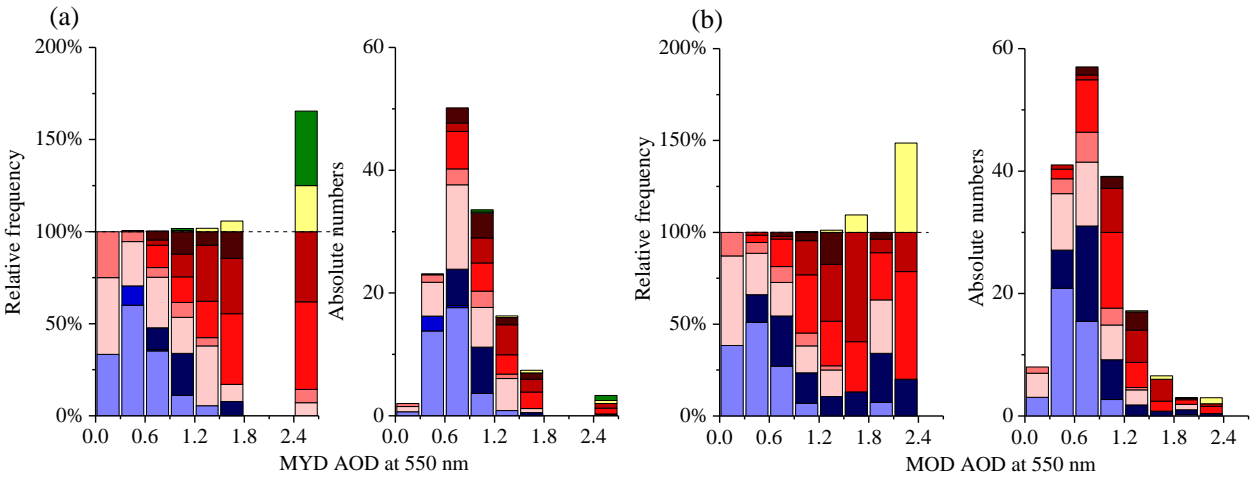

Figure 15. Results of the cloud classification scheme as a function of the aerosol optical depth (AOD) at $550 \mathrm{~nm}$ from MODIS on Aqua (MYD) (a) and on Terra (MOD) (b). The left parts of the figures present the relative frequencies of the different sky conditions (see the caption of Fig. 10). The right parts of the figures present the absolute numbers of the sky conditions.

ference for fog is found between MODIS on Aqua (overpass time: 13:30 LT) and on Terra (overpass time: 10:30 LT). The "continuous clouds (small SZA)" sky condition rarely occurs for GOME-2 due to its early overpass time, because this sky condition only occurs for small SZA.

In Fig. 17 the MAX-DOAS results are compared to the COT derived from MODIS. For this comparison we used only MODIS data with geometrical CF $>80 \%$. Clear sky conditions (with low and high aerosol load) are only found for cases with small COT, which can be interpreted by the same two facts as the comparison with effective CFs. Cases of broken clouds and cloud holes are mainly found for small COT, continuous clouds for medium COT and optically thick clouds for large COT, in agreement with our expectations. Slightly different dependencies are found for both MODIS instruments, especially with respect to the fractions of optically thick clouds and continuous clouds. However, the dif- 
Clear with low aerosol $\square$ Extremely high midday CI $\square$ Clear with high aerosol

Zenith cloud holes $\square$ Off-zenith cloud holes $\square$ Broken clouds $\square$ Continuous clouds (large SZA)

Continuous clouds (small SZA) $\square$ Fog $\square$ Optically thick clouds

(a)

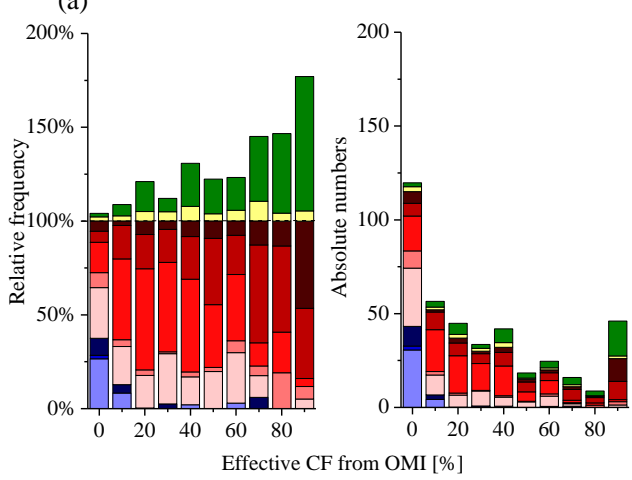

(c)

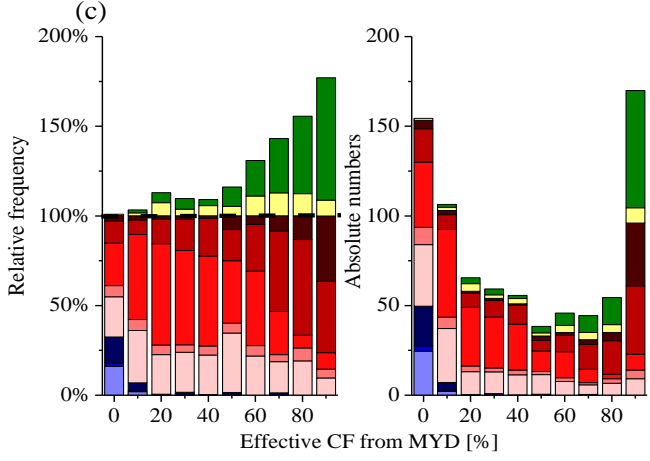

(b)
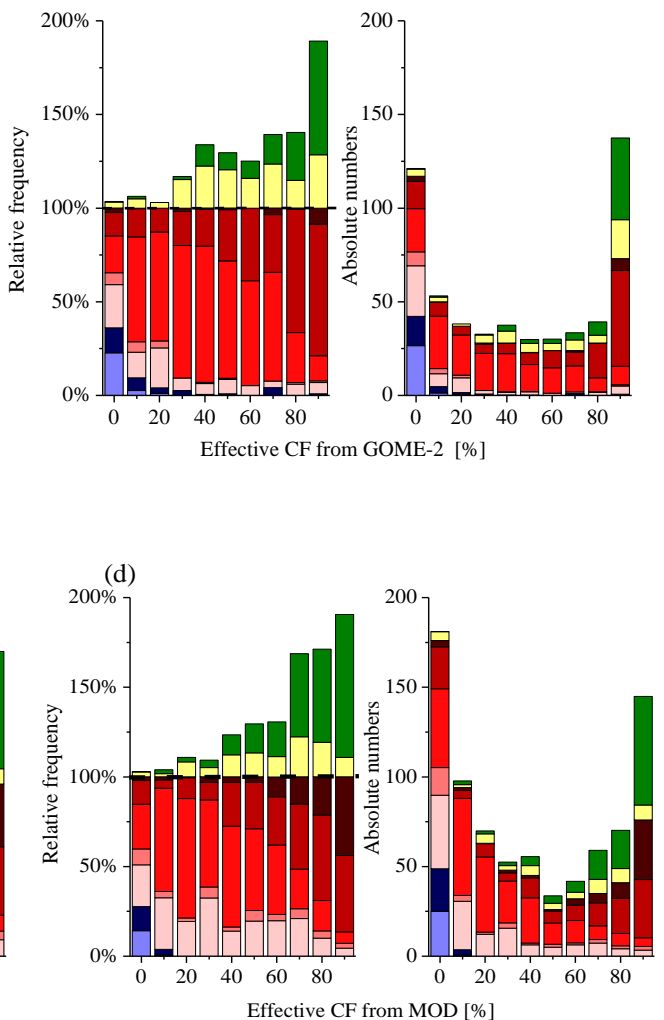

Figure 16. Results of the cloud classification scheme as a function of effective cloud fractions derived from (a) OMI, (b) GOME-2, (c) MODIS on Aqua (MYD) and (d) MODIS on Terra (MOD). The left parts of the figures present the relative frequencies of the different sky conditions (see the caption of Fig. 10). The right parts of the figures present the absolute numbers of the sky conditions.

Clear with low aerosol $\square$ Extremely high midday CI $\square$ Clear with high aerosol

Zenith cloud holes $\square$ Off-zenith cloud holes $\square$ Broken clouds $\square$ Continuous clouds (large SZA)

Continuous clouds (small SZA) $\square$ fog $\square$ Optically thick clouds
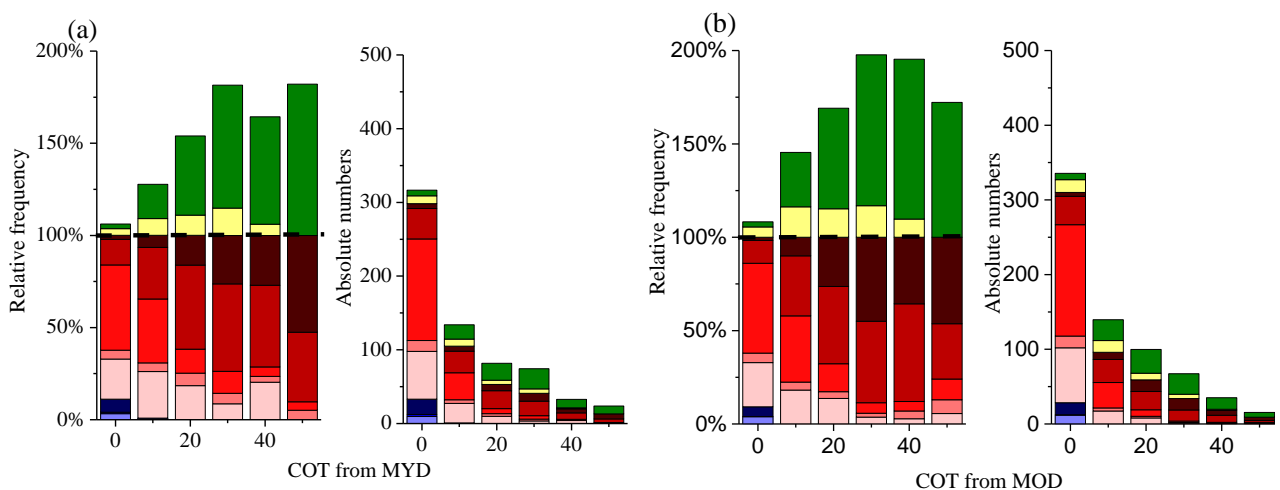

Figure 17. Results of the cloud classification scheme as a function of the cloud optical thickness (COT) from MODIS on Aqua (MYD) (a) and on Terra (MOD) (b), both for measurements with geometrical $\mathrm{CF}>80 \%$ only. The left parts of the figures present the relative frequencies of the different sky conditions (see the caption of Fig. 10). The right parts of the figures present the absolute numbers of the sky conditions. 
Clear with low aerosol $\square$ Extremely high midday CI $\square$ Clear with high aerosol

Zenith cloud holes $\square$ Off-zenith cloud holes $\square$ Broken clouds $\square$ Continuous clouds (large SZA)

Continuous clouds (small SZA) $\square$ Fog $\square$ Optically thick clouds
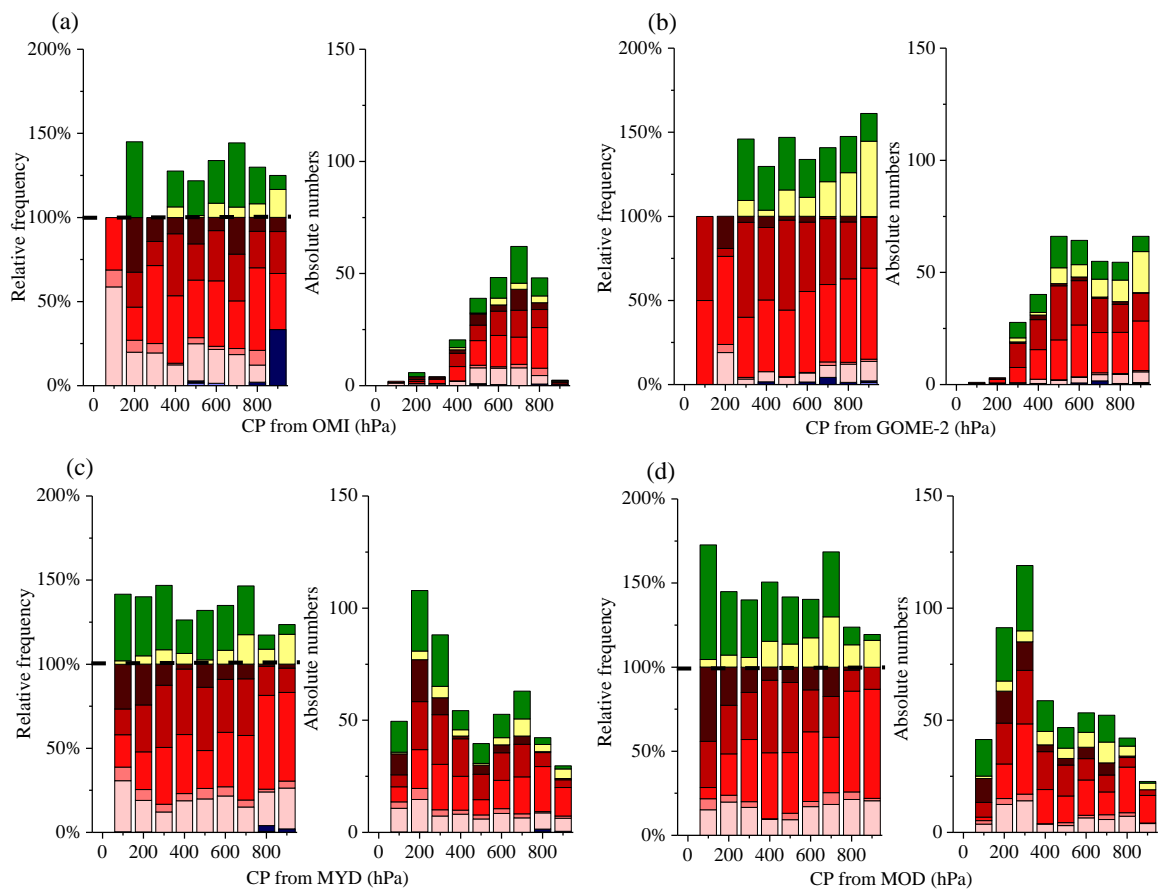

Figure 18. Results of the cloud classification scheme as a function of cloud pressure derived from different satellite observations for effective cloud fraction above 0.2; cloud pressure from (a) OMI, (b) GOME-2, (c) MODIS on Aqua and (d) MODIS on Terra. The left parts of the figures present the relative frequencies of the different sky conditions (see the caption of Fig. 10). The right parts of the figures present the absolute numbers of the sky conditions.

ferences between MODIS instruments are probably not significant in view of the number of data points.

In Fig. 18 the MAX-DOAS results are shown as a function of the cloud pressure derived from OMI, GOME-2 and both MODIS instruments. For the comparison, we used the criteria of effective $\mathrm{CF}$ above $20 \%$ to filter the cloud pressure data from different satellites because the CP cannot be accurately retrieved for few clouds in the satellite view (Weisz et al., 2007; Wang et al., 2008). Similar distributions of the relative frequency of the sky conditions along the cloud pressure are found for all four cases. Continuous clouds have the highest probability for medium cloud pressures, which is probably related to the typical altitudes of stratus clouds. Compared to continuous clouds, broken clouds have larger cloud top pressure, which probably indicates that most broken clouds are cumulus. The category of cloud holes occurs mostly equally in various cloud top pressures. Also fog is usually assigned to high cloud pressures, representing fog events at low altitude (some of them might of course by overlaid by higher clouds). And a much higher frequency of fog is found by GOME-2 compared to other instruments, probably due to its earlier overpass time (09:30 LT). Much fewer absolute numbers of the observed sky conditions are assigned to small $\mathrm{CP}$ from OMI and GOME-2 than that from MODIS, which is well explained by the general overestimation of $\mathrm{CP}$ by OMI and GOME-2 (see the Supplement). A systematic difference in the derived cloud pressures for UV/vis methods (OMI and GOME-2) and IR methods (MODIS) is expected because $\mathrm{UV} / \mathrm{vis}$ methods are sensitive to the cloud center rather than to the cloud top.

Although no clear relationship between the MAX-DOAS results and the satellite cloud pressure can be expected, the findings show that both high and low clouds can be detected using the MAX-DOAS classification scheme.

\subsubsection{Influence of the spatial and temporal averaging on the comparison results}

The OMI and GOME-2 satellite data used for the comparison cover rather large areas (at least $13 \times 26 \mathrm{~km}^{2}$ for OMI and $40 \times 80 \mathrm{~km}^{2}$ for GOME-2). In contrast, MODIS data are available at much finer resolution (see Sect. 2.4.3), e.g., on a $5 \mathrm{~km} \times 5 \mathrm{~km}$ resolution for the MODIS cloud fraction product. Thus we used MODIS data to investigate the influence of the spatial resolution on the comparison results with our classification scheme. We also varied the period over which the MAX-DOAS results are averaged in order to study the influence of the temporal resolution on the comparison results. 
In Fig. 19 the classification results are shown as a function of the MODIS effective cloud fraction for the different spatial and temporal averages. Interestingly, the results hardly depend on the selected temporal and spatial averages. In particular the results for different time averages are almost identical. In contrast, a small effect of the spatial averaging on the classification results is found: if the satellite data are averaged over a larger spatial range, a more clear assignment of the extreme values is found. The fraction of clear sky scenarios (with either low or high aerosol load) and of cloudy scenarios increases for MODIS small (0 to 10\%) and high (90 to $100 \%$ ) cloud fractions, respectively. These findings indicate that if the requirements of either completely clear or cloudy sky are applied for a larger area, the probability is increased that the MAX-DOAS results around the time of the satellite overpass were really clear or cloudy, respectively. The main conclusion from our sensitivity studies is that the selected standard averaging criteria (temporal averaging: $\pm 30 \mathrm{~min}$ around the overpass time; spatial averaging: $0.1^{\circ} \times 0.1^{\circ}$ ) are well suited for the comparisons with satellite data.

\subsubsection{Cloud properties retrieved from satellite observations for clear sky cases identified by MAX-DOAS}

As discussed in the previous section, for part of the clear sky cases (classified from MAX-DOAS observations) the corresponding satellite observations indicate the presence of clouds. There are three possible reasons for this: (1) the satellite instruments wrongly attribute strong aerosol scattering to clouds; (2) the MAX-DOAS classification mistakes clouds for aerosols; (3) the instruments sense different air masses (due to imperfect collocation), and hence different sky conditions. In this section we investigate the sensitivity of the satellite cloud products to the sky condition derived from our cloud classification scheme. We only consider clear sky conditions (with low or high aerosol load). The respective cloud properties derived from the satellite observations are presented in Table 3.

The satellite cloud products are systematically different for cases with either low or high aerosol load. The mean geometrical and effective CFs derived from the four instruments are appreciably larger for cases with high aerosol load than for low aerosol load. This may be an indication that the cloud parameters derived from satellites are indeed sensitive to the presence and amount of aerosols. For MODIS, Brennan et al. (2005) concludes that the aerosol contamination of MODIS Collection 4 cloud products occurs when aerosol optical depth is larger than 0.6. Although the improved Collection 5 cloud products, used in this study, apply an improved cloud masking technique, our finding indicates that the aerosol contamination of MODIS cloud products still occurs. Interestingly, even for cases with low aerosol load, the geometric CF derived from MODIS is $\gg 0$ (with mean COT of about 1), indicating that the MODIS geometric cloud fraction is sensitive even to rather small aerosols loads. For cases with high aerosol load, the COT derived from MODIS is much larger than for cases with low aerosol load. But here it should be noted that for both categories rather small values (optical thickness $<3$ ) are found, which fit quite well to typical optical depths of aerosols at Wuxi (see Fig. 13). It should be noted that the mismatch of the respective fields of view of MODIS and the MAX-DOAS instrument probably also contributes to the retrieved cloud properties. For OMI and GOME-2, the contamination of effective CF by aerosols is also found by Chimot et al. (2014). A study by Wang et al. (2012) showed that the sensitivity of the FRESCO cloud retrieval of GOME-2 to aerosols can be exploited to extract information on the altitude of optically thick aerosol plumes. For the CP, similar (high) values for both categories are found (about $1000 \mathrm{hPa}$ for both MODIS instruments and ca. $800 \mathrm{hPa}$ for GOME-2 and OMI), indicating that the aerosols are located close to the surface. However, $\mathrm{CP}$ retrieval errors are quite large for effective CF below $20 \%$.

We cannot exclude the possibility that the MAX-DOAS classification occasionally mistakes clouds for aerosols, and imperfect collocation certainly leads to occasional mismatching of MAX-DOAS and satellite measurements. Nevertheless, our findings indicate that the satellite cloud products contain valuable information on aerosols. Especially conditions of high aerosol load are likely to be identified as low clouds with low optical thickness.

\section{Discussion and conclusion}

We adapted the MAX-DOAS cloud classification scheme developed by Wagner et al. (2014) and applied it to long-term MAX-DOAS measurements (2011 to 2013) in Wuxi, China $\left(31.57^{\circ} \mathrm{N}, 120.31^{\circ} \mathrm{E}\right)$. While the features of the classification scheme are basically the same as in the original classification scheme, a few modifications were applied, taking into account the specific properties of the instrument at Wuxi and the atmospheric conditions at the measurement site.

a. We developed a simple method for the quantification and correction for the effects of possible instrument degradation. Such a correction becomes especially important when extended time series are investigated.

b. Due to the specific instrumental response function of the Wuxi instrument and the specific atmospheric properties during the days used for the calibration of the measured radiance and the $\mathrm{CI}$, a new set of threshold values had to be determined.

c. Because of the low SZA, which occurs at Wuxi in summer, we extended the cloud classification scheme by using an additional criterion for the determination of continuous clouds at small SZA. This modification will be 
(a)

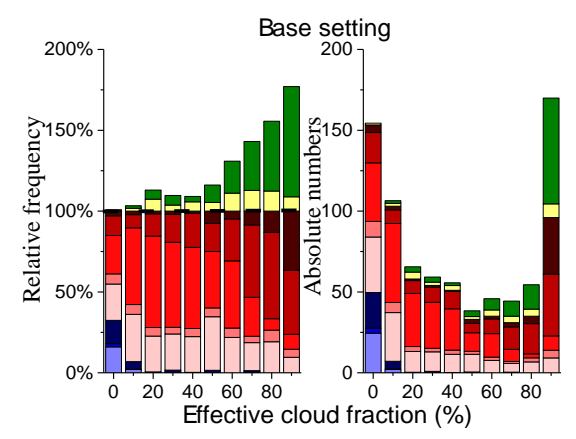

(b)

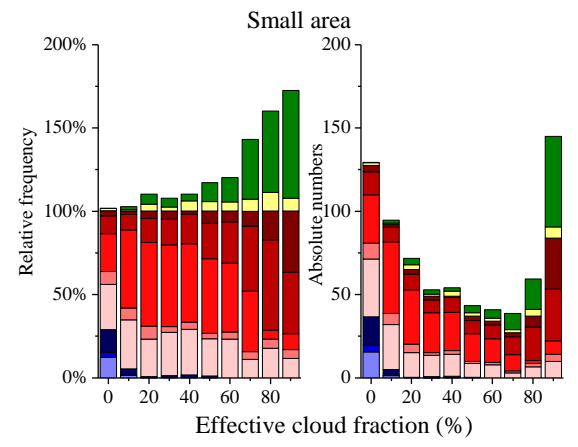

(d)

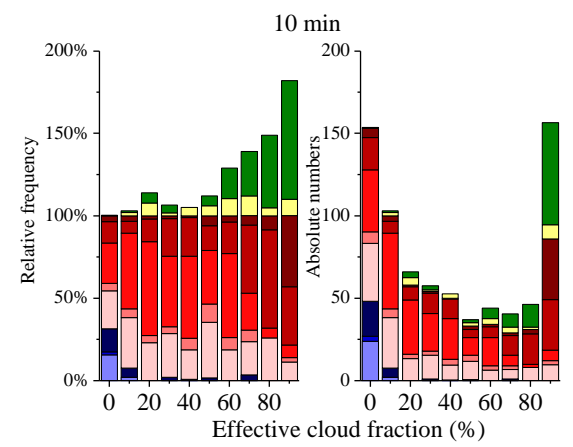

(c)

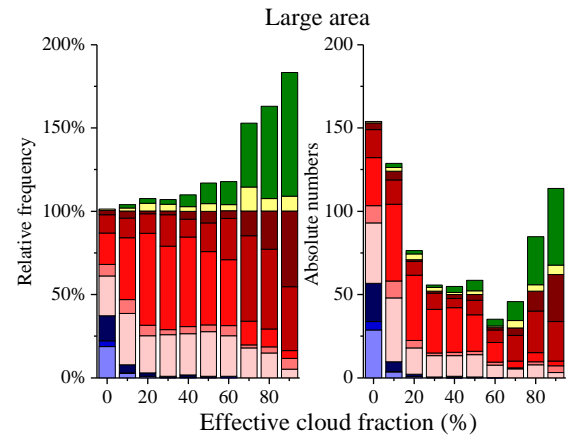

(e)

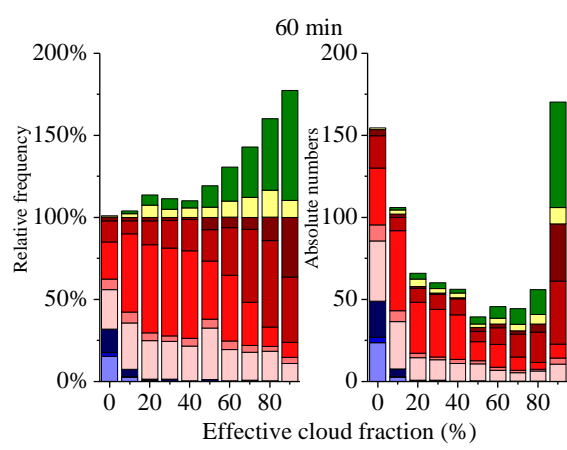

Figure 19. Results of the cloud classification scheme as a function of the effective cloud fraction derived from MODIS (AQUA) for different temporal and spatial averages. (a) Results for the standard settings, spatial averaging of MODIS data: $0.1^{\circ} \times 0.1^{\circ}$, temporal averaging of MAX-DOAS data: $\pm 30 \mathrm{~min}$ (same as in Fig. 16c); (b) results for spatial averaging of MODIS data: $0.05^{\circ} \times 0.05^{\circ}$; (c) results for spatial averaging of MODIS data: $0.2^{\circ} \times 0.2^{\circ}$; (d) results for temporal averaging of MAX-DOAS data: \pm 10 min; (e) results for temporal averaging of MAX-DOAS data: $\pm 60 \mathrm{~min}$.

Table 3. Average values of various cloud properties derived from the MODIS on Aqua (MYD) and on Terra (MOD) as well as GOME-2 and OMI for clear sky conditions with low or high aerosols (as identified by MAX-DOAS). The missing values mean that the corresponding quantities are not provided by the relevant instrument data set. "Low aerosol" and "high aerosol" in the second row refer to the "clear sky with low aerosol load" and "clear sky with high aerosol load" sky conditions identified by the MAX-DOAS scheme, respectively.

\begin{tabular}{|c|c|c|c|c|c|c|c|c|}
\hline & \multicolumn{2}{|c|}{ MYD } & \multicolumn{2}{|c|}{ MOD } & \multicolumn{2}{|c|}{ OMI } & \multicolumn{2}{|c|}{ GOME2 } \\
\hline & $\begin{array}{l}\text { low } \\
\text { aerosol }\end{array}$ & $\begin{array}{l}\text { high } \\
\text { aerosol }\end{array}$ & $\begin{array}{l}\text { low } \\
\text { aerosol }\end{array}$ & $\begin{array}{l}\text { high } \\
\text { aerosol }\end{array}$ & $\begin{array}{l}\text { low } \\
\text { aerosol }\end{array}$ & $\begin{array}{l}\text { high } \\
\text { aerosol }\end{array}$ & $\begin{array}{l}\text { low } \\
\text { aerosol }\end{array}$ & $\begin{array}{l}\text { high } \\
\text { aerosol }\end{array}$ \\
\hline Geometrical cloud fraction & $30 \%$ & $63 \%$ & $32 \%$ & $49 \%$ & & & & \\
\hline Effective cloud fraction & $2 \%$ & $4 \%$ & $1 \%$ & $2 \%$ & $7 \%$ & $13 \%$ & $2 \%$ & $14 \%$ \\
\hline Cloud optical thickness & 1 & 3 & 0.8 & 1.3 & & & & \\
\hline
\end{tabular}


especially important for measurements during summer at latitudes between $\pm 60^{\circ}$. In addition, we added a category named extremely high midday CI, which describes very rare cases again at small SZA with strongly reduced radiances in the blue spectral range compared to the UV.

d. Optically thick clouds were identified only based on the measured radiances because of the challenge of the absolute calibration of the $\mathrm{O}_{4}$ retrieval for the long measurement time series. We compared the results of our MAX-DOAS cloud classification scheme with several independent data sets: AOD from AERONET and MODIS, visibility derived from a visibility meter, as well as effective cloud fractions, cloud top pressures and cloud optical thickness derived from different satellite instruments (MODIS, OMI and GOME-2). Here it should be noted that no quantitative comparison between the MAX-DOAS results and the independent data sets is possible, because (a) not exactly the same quantities are measured, and (b) the spatial and temporal sampling is quite different. Thus our comparison is performed in a semi-quantitative way; the MAX-DOAS cloud classification results are studied as a function of the external quantities. These statistical analyses overall confirmed the validity of our classification scheme. For example, most cases of clear sky conditions with low or high aerosol load were correctly assigned to the respective AOD derived from AERONET and MODIS. Also the dependence of the cloud classification results on cloud optical thickness and effective cloud fraction derived from satellite was well represented.

The dependence of the results of the MAX-DOAS cloud classification scheme on the cloud optical thickness motivated us to further investigate the general ability of the scheme to identify optically thin clouds. For MODIS observations of thick clouds (COT > 10), the sky conditions derived from MAX-DOAS comprise mostly optically thick clouds, continuous clouds and fog. For MODIS observations of thin clouds $($ COT $<10)$, the sky conditions derived from MAX-DOAS mainly consist of broken clouds and cloud holes. However, a few measurements characterized as clear sky with low or high aerosol load are also assigned to this category. This may be caused by occasional misclassification of the high aerosol load as optically thin clouds by the satellite cloud retrieval algorithms, but may also have to do with the observation of different air masses by the different instruments, or incorrect classification of the sky condition by the MAXDOAS scheme (see Sect. 3.2.5). While the misclassification of aerosol as clouds describes a fundamental problem for cloud retrievals, this finding also indicates the potential to derive information on aerosol properties from satellite measurements of cloud fraction and cloud pressure.

From our comparison study it is not possible to quantitatively assess the uncertainty of our cloud classification scheme. But we investigated the effect of changes of the chosen threshold values on the classification results. While the influence of these changes is very small for most quantities, for the threshold of the CI, a strong influence on the assignment to different sky conditions was found. In particular, the partitioning to clear sky conditions with either low aerosol or high aerosol load depends critically on this choice. Based on the observed dependencies of the assignments to these two classes, we conclude that the selected threshold value for the $\mathrm{CI}$ in our study was a very reasonable choice. From the comparison with AERONET AOD measurements we can particularly estimate the AOD value for the transition between high and low aerosols loads. We find a value of the AOD of about 0.5 , which is very reasonable.

We also investigated the effect of the temporal and spatial averaging of the MAX-DOAS and satellite data on the comparison results. For the investigated ranges (the temporal averaging of the MAX-DOAS data was varied between 20 and $120 \mathrm{~min}$; the spatial averaging of the satellite data was varied between $0.05^{\circ} \times 0.05^{\circ}$ and $0.2^{\circ} \times 0.2^{\circ}$ ) almost the same classification results were found. We only found a slightly better assignment of both totally clear and totally cloudy classification results to the corresponding extreme satellite cloud fractions for the largest area of spatial averaging $\left(0.2^{\circ} \times 0.2^{\circ}\right)$.

We conclude that the MAX-DOAS cloud classification scheme works well in general, not only in cases of optically thick clouds, but also for most optically thin clouds. In addition, we find that even high clouds (cloud pressure $<500 \mathrm{hPa}$ ) are well identified by the MAX-DOAS cloud classification scheme (Fig. 18), at least if their effective CF $>20 \%$.

In summary, in this study we extended the MAXDOAS cloud classification scheme developed by Wagner et al. (2014) to MAX-DOAS measurements over long periods and also for small SZA. In future studies, we will apply the MAX-DOAS classification results to improve the validation of satellite products of tropospheric trace gases by MAXDOAS measurements.

\section{The Supplement related to this article is available online at doi:10.5194/amt-8-5133-2015-supplement.}

Acknowledgements. We thank the Wuxi Chinese Academy of Sciences Photonics Corporation for their contributions in carrying out the observations of the MAX-DOAS instrument and the visibility meter in Wuxi. We thank Goddard Space Flight Center, NASA, for their freely accessible archive of AERONET and MODIS data. We thank Ma Ronghua, Nanjing Institute of Geography \& Limnology Chinese Academy of Sciences, for his effort in operating the Taihu AERONET station. We thank the Royal Netherlands Meteorological Institute for their freely accessible archive of OMI and GOME-2 data. This work was supported by Max Planck 
Society-Chinese Academy of Sciences Joint Doctoral Promotion Programme, and the Special Project of Environmental Nonprofit Industry Research, China (grant no.: 201109007) and National Natural Science Foundation of China (grant no.: 41275038).

The article processing charges for this open-access publication were covered by the Max Planck Society.

Edited by: O. Torres

\section{References}

Acarreta, J. R., De Haan, J. F., and Stammes P.: Cloud pressure retrieval using the $\mathrm{O}_{2}-\mathrm{O}_{2}$ absorption band at $477 \mathrm{~nm}$, J. Geophys. Res., 109, D05204, doi:10.1029/2003JD003915, 2004.

Baum, B. A. and Platnick S.: Introduction to MODIS cloud products, in: Earth science satellite remote sensing, edited by: Qu, J. J., Gao, W., Kafatos,M., Murphy, R. E., and Salomonson, V. V., 74-91, Springer Berlin Heidelberg, 2006.

Bobrowski, N., Honninger, G., Galle, B., and Platt, U.: Detection of bromine monoxide in a vol-canic plume, Nature, 423, 273-276, 2003.

Boersma, K. F., Eskes, H. J., and Brinksma, E. J.: Error Analysis for Tropospheric $\mathrm{NO}_{2}$ Retrieval from Space, J. Geophys. Res., 109, D04311, doi:10.1029/2003JD003962, 2004.

Boersma, K. F., Eskes, H. J., Veefkind, J. P., Brinksma, E. J., van der A, R. J., Sneep, M., van den Oord, G. H. J., Levelt, P. F., Stammes, P., Gleason, J. F., and Bucsela, E. J.: Near-real time retrieval of tropospheric $\mathrm{NO}_{2}$ from OMI, Atmos. Chem. Phys., 7, 2103-2118, doi:10.5194/acp-7-2103-2007, 2007.

Brennan, J. I., Kaufman, Y. J., Koren, I., and Li, R. R.: Aerosol-cloud interaction-misclassification of MODIS clouds in heavy aerosol, Geoscience and Remote Sensing, 43, 911, doi:10.1109/TGRS.2005.844662, 2005.

Callies, J., Corpaccioli, E., Eisinger, M., Hahne, A., and Lefebvre, A.: GOME-2 - MetOp's Second Generation Sensor for Operational Ozone Monitoring, ESA Bulletin, 102, 28-36, 2000.

Chimot, J., Veefkind J. P., Vlemmix T., Levelt P. F.: Analysis of the aerosol effects on the current NO2 and cloud retrievals from the OMI satellite instrument, EOS Aura Science Team Meeting 10th year anniversary celebration, College Park, MD, USA, 15 September 2014.

Clémer, K., Fayt, C., Hendrick, F., Hermans, C., Pinardi, G., Van Roozendael, M.: The simultaneous retrieval of tropospheric aerosol extinction and $\mathrm{NO}_{2}$ vertical profiles from MAXDOAS measurements in Beijing, in: Proceedings of the 8th International Symposium on Tropospheric Profiling, ISBN: 978-90-6960-2332, Delft, the Netherlands, 19-23 October 2009.

Clémer, K., Van Roozendael, M., Fayt, C., Hendrick, F., Hermans, C., Pinardi, G., Spurr, R., Wang, P., and De Mazière, M.: Multiple wavelength retrieval of tropospheric aerosol optical properties from MAXDOAS measurements in Beijing, Atmos. Meas. Tech., 3, 863-878, doi:10.5194/amt-3-863-2010, 2010.

Deutschmann, T., Beirle, S., Frieß, U., Grzegorski, M., Kern, C., Kritten, L., Platt, U., Pukite, J., Wagner, T., Werner, B., and Pfeilsticker, K.: The Monte Carlo Atmospheric Radiative Transfer Model McArtim: introduction and validation of Jacobians and 3-D features, J. Quant. Spec-trosc. Ra., 112, 1119-1137, doi:10.1016/j.jqsrt.2010.12.009, 2011.

Erle, F., Pfeilsticker, K., and Platt, U: On the influence of tropospheric clouds on zenith scattered light measurements of stratospheric species, Geophys. Res. Lett., 22, 2725-2728, 1995.

Frieß, U., Monks, P. S., Remedios, J. J., Rozanov A., Sinreich R., Wagner T., and Platt, U.: MAX-DOAS $\mathrm{O}_{4}$ measurements: A new technique to derive information on atmospheric aerosols: 2. Modeling studies, J. Geophys. Res., 111, D14203, doi:10.1029/2005JD006618, 2006.

Frieß U, Sihler H, Sander R. The vertical distribution of $\mathrm{BrO}$ and aerosols in the Arctic: Measurements by active and passive differential optical absorption spectroscopy, J. Geophys. Res., 116, D00R04, doi:10.1029/2011JD015938, 2011.

Gielen, C., Van Roozendael, M., Hendrick, F., Pinardi, G., Vlemmix, T., De Bock, V., De Backer, H., Fayt, C., Hermans, C., Gillotay, D., and Wang, P.: A simple and versatile cloudscreening method for MAX-DOAS retrievals, Atmos. Meas. Tech., 7, 3509-3527, doi:10.5194/amt-7-3509-2014, 2014.

Hartl, A. and Wenig, M. O.: Regularisation model study for the least-squares retrieval of aerosol extinction time series from UV/VIS MAX-DOAS observations for a ground layer profile parameterisation, Atmos. Meas. Tech., 6, 1959-1980, doi:10.5194/amt-6-1959-2013, 2013.

Heckel, A., Richter, A., Tarsu, T., Wittrock, F., Hak, C., Pundt, I., Junkermann, W., and Burrows, J. P.: MAX-DOAS measurements of formaldehyde in the Po-Valley, Atmos. Chem. Phys., 5, 909918, doi:10.5194/acp-5-909-2005, 2005.

Henyey, L. G. and Greenstein J. L.: Diffuse radiation in the galaxy, Astrophys. J., 93, 70-83, 1941.

Holben, B. N., Eck, T. F., Slutsker, I., Tanre, D., Buis, J. P., Setzer, A., Vermote, E., Reagan, J. A., Kaufman, Y., Nakajima, T., Lavenu, F., Jankowiak, I., and Smirnov, A.: AERONET - A federated instrument network and data archive for aerosol characterization, Remote Sens. Environ., 66, 1-16, 1998.

Holben, B. N., Tanre, D., Smirnov, A., Eck, T. F., Slutsker, I., Abuhassan, N., Newcomb, W. W., Schafer, J., Chatenet, B., Lavenue, F., Kaufman, Y. J., Van de Castle, J., Setzer, A., Markham, B., Clark, D., Frouin, R., Halthore, R., Karnieli, A., O’Neill, N. T., Pietras, C., Pinker, R. T., Voss, K., and Zibordi, Z.: An emerg-ing ground-based aerosol climatology: Aerosol optical depth from AERONET, J. Geophys. Res., 106, 12067-12097, 2001.

Hönninger, G., von Friedeburg, C., and Platt, U.: Multi axis differential optical absorption spectroscopy (MAX-DOAS), Atmos Chem. Phys., 4, 231-254, doi:10.5194/acp-4-231-2004, 2004.

Irie, H., Kanaya, Y., Akimoto, H., Iwabuchi, H., Shimizu, A., and Aoki, K.: First retrieval of tropospheric aerosol profiles using MAX-DOAS and comparison with lidar and sky radiometer measurements, Atmos. Chem. Phys., 8, 341-350, doi:10.5194/acp-8341-2008, 2008.

Irie, H., Takashima, H., Kanaya, Y., Boersma, K. F., Gast, L., Wittrock, F., Brunner, D., Zhou, Y., and Van Roozendael, M.: Eightcomponent retrievals from ground-based MAX-DOAS observations, Atmos. Meas. Tech., 4, 1027-1044, doi:10.5194/amt-41027-2011, 2011.

Kaufman, Y. J., Tanré, D., and Boucher, O.: A satellite view of aerosols in the climate system, Nature, 419, 215-223, 2002. 
King, M. D., Tsay, S. -C., Platnick, S. E., Wang, M., and Liou, K. -N.: Cloud retrieval algorithms for MODIS: Optical thickness, effective particle radius, and thermodynamic phase, Tech. Rep. ATBD-MOD-05, NASA, Washington, DC, 46-41, 1998.

King, M. D., Platnick, S., Yang, P., Arnold, G. T., Gray, M.A., Riédi, J. C., Ackerman, S. A., and Liou, K. N.: Remote sensing of liquid water and ice cloud optical thickness, and effective radius in the arctic: Application of airborne multispectral MAS data, J. Atmos. Oceanic Technol., 21, 857-875, 2004.

Levelt, P. F., Hilsenrath, E., Lepppelmeier, G. W., van den Oord, G. H. J., Bhartia, P. K., Taminnen, J., de Haan, J. F., and Veefkind, J. P.: Science objectives of the Ozone Monitoring Instrument, IEEE Trans. Geosci. Remote Sens., 44, 1199-1208, 2006 a.

Levelt, P. F., van den Oord, G. H. J., Dobber, M. R., Malkki, A., Visser, H., de Vries, J., Stammes, P., Lundell, J., and Saari, H.: The Ozone Monitoring Instrument, IEEE Trans. Geosci. Remote Sens., 44, 1093-1101, 2006b.

Levy, R. C., Remer, L. A., Kleidman, R. G., Mattoo, S., Ichoku, C., Kahn, R., and Eck, T. F.: Global evaluation of the Collection 5 MODIS dark-target aerosol products over land, Atmos. Chem. Phys., 10, 10399-10420, doi:10.5194/acp-10-10399-2010, 2010.

Li, A., Xie, P. H., Liu, C., Liu, J. G., and Liu, W. Q.: A scanning muti-Axis differential optical absorption spectroscopy system for measurement of tropospheric $\mathrm{NO}_{2}$ in Beijing, Chin. Phys. Lett., 24, 2859-2862, 2007.

Li, X., Brauers, T., Shao, M., Garland, R. M., Wagner, T., Deutschmann, T., and Wahner, A.: MAX-DOAS measurements in southern China: retrieval of aerosol extinctions and validation using ground-based in-situ data, Atmos. Chem. Phys., 10, 20792089, doi:10.5194/acp-10-2079-2010, 2010.

Li, X., Brauers, T., Hofzumahaus, A., Lu, K., Li, Y. P., Shao, M., Wagner, T., and Wahner, A.: MAX-DOAS measurements of $\mathrm{NO}_{2}, \mathrm{HCHO}$ and $\mathrm{CHOCHO}$ at a rural site in Southern China, Atmos. Chem. Phys., 13, 2133-2151, doi:10.5194/acp-13-21332013, 2013.

Ma, J. Z., Beirle, S., Jin, J. L., Shaiganfar, R., Yan, P., and Wagner, T.: Tropospheric $\mathrm{NO}_{2}$ vertical column densities over Beijing: results of the first three years of ground-based MAX-DOAS measurements (2008-2011) and satellite validation, Atmos. Chem. Phys., 13, 1547-1567, doi:10.5194/acp-13-1547-2013, 2013.

Munro, R., Eisinger, M., Anderson, C., Callies, J., Corpaccioli, E., Lang, R., Lefebvre, A., Livschitz, Y., and Perez Albinana, A.: GOME-2 on MetOp: From in-orbit verification to routine operations, in: Proceedings of EUMETSAT Meteorological Satellite Conference, Helsinki, Finland, 12-16 June 2006.

Munro, R., Lang, R., Klaes, D., Poli, G., Retscher, C., Lindstrot, R., Huckle, R., Lacan, A., Grzegorski, M., Holdak, A., Kokhanovsky, A., Livschitz, J., and Eisinger, M.: The GOME2 instrument on the Metop series of satellites: instrument design, calibration, and level 1 data processing - an overview, Atmos. Meas. Tech. Discuss., 8, 8645-8700, doi:10.5194/amtd-8-86452015, 2015.

Nebuloni, R.: Empirical relationships between extinction coefficient and visibility in fog, Appl. Opt., 44, 3795-3804, doi:10.1364/AO.44.003795, 2005.

Pikelnaya, O., Hurlock, S. C., Trick, S., and Stutz, J.: Intercomparison of multiaxis and long-path optical absorption spectroscopy measurements in the marine boundary layer, J. Geophys. Res., 112, D10S01, doi:10.1029/2006JD007727, 2007.
Piters, A. J. M., Boersma, K. F., Kroon, M., Hains, J. C., Van Roozendael, M., Wittrock, F., Abuhassan, N., Adams, C., Akrami, M., Allaart, M. A. F., Apituley, A., Beirle, S., Bergwerff, J. B., Berkhout, A. J. C., Brunner, D., Cede, A., Chong, J., Clémer, K., Fayt, C., Frieß, U., Gast, L. F. L., Gil-Ojeda, M., Goutail, F., Graves, R., Griesfeller, A., Großmann, K., Hemerijckx, G., Hendrick, F., Henzing, B., Herman, J., Hermans, C., Hoexum, M., van der Hoff, G. R., Irie, H., Johnston, P. V., Kanaya, Y., Kim, Y. J., Klein Baltink, H., Kreher, K., de Leeuw, G., Leigh, R., Merlaud, A., Moerman, M. M., Monks, P. S., Mount, G. H., Navarro-Comas, M., Oetjen, H., Pazmino, A., Perez-Camacho, M., Peters, E., du Piesanie, A., Pinardi, G., Puentedura, O., Richter, A., Roscoe, H. K., Schönhardt, A., Schwarzenbach, B., Shaiganfar, R., Sluis, W., Spinei, E., Stolk, A. P., Strong, K., Swart, D. P. J., Takashima, H., Vlemmix, T. Vrekoussis, M., Wagner, T., Whyte, C., Wilson, K. M., Yela, M., Yilmaz, S., Zieger, P., and Zhou, Y.: The Cabauw Intercomparison campaign for Nitrogen Dioxide measuring Instruments (CINDI): design, execution, and early results, Atmos. Meas. Tech., 5, 457-485, doi:10.5194/amt-5-457-2012, 2012.

Platnick, S., King, M. D., Ackerman, S. A., Menzel, W. P., Baum, B. A., Riédi, J. C., and Frey, R. A.: The MODIS cloud products: algorithms and examples from Terra, IEEE Trans. Geosci. Remote. Sens., 41, 459-473, 2003.

Platt, U. and Stutz, J.: Differential Optical Absorption Spectroscopy. Springer-Verlag Heidelberg, Berlin, 229-375, 2008.

Remer, L. A, Kaufman, Y. J, Tanre, D., Mattoo, S., Chu, D. A. , Martins, J. V., Li, R. R., Ichoku, C., Levy, R. C., Kleidman, R. G., Eck, T. F., Vermote, E., Holben, B. N.: The MODIS aerosol algorithm, products, and validation, J. Atmos. Sci., 62, 947-973, 2005.

Sarkissian, A., Pommereau, J. P., and Goutail, F.: Identification of polar stratospheric clouds from the ground by visible spectrometry, J. Geophys. Res., 18, 779-782, doi:10.1029/91GL00769, 1991.

Sinreich, R., Volkamer, R., Filsinger, F., Frieß, U., Kern, C., Platt, U., Sebastián, O., and Wagner, T.: MAX-DOAS detection of glyoxal during ICARTT 2004, Atmos. Chem. Phys., 7, 1293-1303, doi:10.5194/acp-7-1293-2007, 2007.

Smirnov, A., Holben, B. N., Eck, T. F., Dubovik, O., and Slutsker, I.: Cloud-Screening and Quality Control Algorithms for the AERONET Database, Remote Sens. Environ., 73, 337-349, 2000.

Sneep, M., De Haan, J. F., Stammes, P., Wang, P., Vanbauce, C., Joiner, J., Vasilkov, A., and Levelt, P.: Three-way comparison between OMI and PARASOL cloud pressure products, J. Geophys. Res., 113, D15S23, doi:10.1029/2007JD008694, 2008.

Solomon, S., Schmeltekopf, A. L., and Sanders, R. W.: On the interpretation of zenith sky absorption measurements, J. Geophys. Res., 92, 8311-8319, 1987.

Stammes, P., Sneep, M., de Haan, J. F., Veefkind, J. P., Wang, P., and Levelt, P. F.: Effective cloud fractions from the Ozone Monitoring Instrument: Theoretical framework and validation, J. Geophys. Res., 113, D16S38, doi:10.1029/2007JD008820, 2008.

Takashima, H., Irie, H., Kanaya, Y., Shimizu, A., Aoki, K., and Akimoto, H.: Atmospheric aerosol variations at Okinawa Island in Japan observed by MAX-DOAS using a new cloud-screening method, J. Geophys. Res., 114, D18213, doi:10.1029/2009JD011939, 2009. 
Theys, N., Van Roozendael, M., Hendrick, F., Fayt, C., Hermans, C., Baray, J.-L., Goutail, F., Pommereau, J.-P., and De Mazière, M.: Retrieval of stratospheric and tropospheric $\mathrm{BrO}$ columns from multi-axis DOAS measurements at Reunion Island $\left(21^{\circ} \mathrm{S}\right.$, $56^{\circ}$ E), Atmos. Chem. Phys., 7, 4733-4749, doi:10.5194/acp-74733-2007, 2007.

Vlemmix, T., Piters, A. J. M., Stammes, P., Wang, P., and Levelt, P. F.: Retrieval of tropospheric NO2 using the MAX-DOAS method combined with relative intensity measurements for aerosol correction, Atmos. Meas. Tech., 3, 1287-1305, doi:10.5194/amt-31287-2010, 2010.

Vlemmix, T., Piters, A. J. M., Berkhout, A. J. C., Gast, L. F. L., Wang, P., and Levelt, P. F.: Ability of the MAX-DOAS method to derive profile information for NO2: can the boundary layer and free troposphere be separated?, Atmos. Meas. Tech., 4, 26592684, doi:10.5194/amt-4-2659-2011, 2011.

Vlemmix, T., Hendrick, F., Pinardi, G., De Smedt, I., Fayt, C., Hermans, C., Piters, A., Wang, P., Levelt, P., and Van Roozendael, M.: MAX-DOAS observations of aerosols, formaldehyde and nitrogen dioxide in the Beijing area: comparison of two profile retrieval approaches, Atmos. Meas. Tech., 8, 941-963, doi:10.5194/amt-8-941-2015, 2015.

Wagner, T., Erie, F., Marquard, L., Otten, C., Pfeilsticker, K., Senne, T., Stutz, J., and Platt, U.: Cloudy sky optical paths as derived from differential optical absorption spectroscopy observations, J. Geophys. Res., 103, 25307, doi:10.1029/98JD01021, 1998.

Wagner, T., Friedeburg, C. von, Wenig M., Otten, C., and Platt, U.: UV/vis observations of atmospheric O4 absorptions using direct moon light and zenith scattered sunlight under clear and cloudy sky conditions, J. Geophys. Res., 107, D204424, doi:10.1029/2001JD001026, 2002.

Wagner, T., B. Dix, C. von Friedeburg, Frieß, U., Sanghavi, S., Sinreich, R., and Platt, U.: MAX-DOAS $\mathrm{O}_{4}$ measurements: A new technique to derive information on atmospheric aerosols - Principles and information content, J. Geophys. Res., 109, D22205, doi:10.1029/2004JD004904, 2004.

Wagner, T., Beirle, S., and Deutschmann, T.: Three-dimensional simulation of the Ring effect in observations of scattered sun light using Monte Carlo radiative transfer models, Atmos. Meas. Tech., 2, 113-124, doi:10.5194/amt-2-113-2009, 2009.

Wagner, T., Beirle, S., Brauers, T., Deutschmann, T., Frieß, U., Hak, C., Halla, J. D., Heue, K. P., Junkermann, W., Li, X., Platt, U., and Pundt-Gruber, I.: Inversion of tropospheric profiles of aerosol extinction and $\mathrm{HCHO}$ and $\mathrm{NO}_{2}$ mixing ratios from MAX-DOAS observations in Milano during the summer of 2003 and comparison with independent data sets, Atmos. Meas. Tech., 4, 2685-2715, doi:10.5194/amt-4-2685-2011, 2011.
Wagner, T., Apituley, A., Beirle, S., Dörner, S., Friess, U., Remmers, J., and Shaiganfar, R.: Cloud detection and classification based on MAX-DOAS observations, Atmos. Meas. Tech., 7, 1289-1320, doi:10.5194/amt-7-1289-2014, 2014.

Wang, P., Stammes, P., van der A, R., Pinardi, G., and van Roozendael, M.: FRESCO+: an improved O2 A-band cloud retrieval algorithm for tropospheric trace gas retrievals, Atmos. Chem. Phys., 8, 6565-6576, doi:10.5194/acp-8-6565-2008, 2008.

Wang, P., Tuinder, O. N. E., Tilstra, L. G., de Graaf, M., and Stammes, P.: Interpretation of FRESCO cloud retrievals in case of absorbing aerosol events, Atmos. Chem. Phys., 12, 90579077, doi:10.5194/acp-12-9057-2012, 2012.

Weisz, E., Li, J., Menzel, W. P., Heidinger, A. K., Kahn, B. H., and Liu, C. Y.: Comparison of AIRS, MODIS, CloudSat and CALIPSO cloud top height retrievals, Geophys. Res. Lett., 34, L17811, doi:10.1029/2007GL030676, 2007.

Wielicki, B. A. and Coakley, Jr, J. A.: Cloud Retrieval Using Infrared Sounder Data: Error Analysis, J. Appl. Meteor., 20, 157$169,1981$.

Winterrath, T., Koruso, T. P., Richter, A., and Burrows, J. P.: Enhanced $\mathrm{O}_{3}$ and $\mathrm{NO}_{2}$ in thunderstorm clouds: convection or production, Geophys. Res. Lett., 26, 1291-1294, doi:10.1029/1999GL900243, 1999.

Wittrock, F., Oetjen, H., Richter, A., Fietkau, S., Medeke, T., Rozanov, A., and Burrows, J. P.: MAX-DOAS measurements of atmospheric trace gases in Ny-Ålesund - Radiative transfer studies and their application, Atmos. Chem. Phys., 4, 955-966, doi:10.5194/acp-4-955-2004, 2004.

Yilmaz, S.: Retrieval of Atmospheric Aerosol and Trace Gas Vertical Profiles using Multi-Axis Differential Optical Absorption Spectroscopy, Dissertation submitted to the Combined Faculties for the Natural Sciences and for Mathematics of the RupertoCarola University of Heidelberg, Germany for the degree of Doctor of Natural Sciences, 83-110, 2012.

Zhao, W. J., Zhang, N., and Sun, J. N.: Spatiotemporal variations of cloud amount over the Yangtze River Delta, China, Journal of Meteorological Research, 28, 371-380, 2014. 